\title{
THE EFFECTIVENESS OF IF-MADM (INTUITIONISTIC-FUZZY MULTI-ATTRIBUTE DECISION-MAKING) FOR GROUP DECISIONS: METHODS AND AN EMPIRICAL ASSESSMENT FOR THE SELECTION OF A SENIOR CENTRE
}

\author{
Zheng-Yun ZHUANG ${ }^{11,4}$, Chia-Rong SU², Shu-Chin CHANG ${ }^{3 *}$ \\ ${ }^{1}$ Department of Civil Engineering, National Kaohsiung University of Science and Technology, \\ No. 415, Jiangong Rd., Sanmin Dist., Kaohsiung City 80778, Taiwan \\ ${ }^{2}$ The Graduate Institute of Business Management, Chang Gung University, \\ 259 Wenhua 1st Road, Guishan Dist., Taoyuan City 33302, Taiwan \\ ${ }^{3}$ Department of Accounting, Chung Yuan Christian University, \\ 200 Chung Pei Road, Chung Li Dist., Taoyuan City 32023, Taiwan \\ ${ }^{4}$ Faculty of Science and Technology, Universidade de Macau, Bldg. N21, Avenida da Vitoria, \\ Ilha da Montanha, Taipa, Macao
}

Received 05 July 2016; accepted 14 October 2018

\begin{abstract}
This study determines the effectiveness of intuitionistic-fuzzy multi-attribute decisionmaking (IF-MADM) for making group decisions in practice. The effectiveness of the method is measured in terms of four dimensions: applicability, efficacy, efficiency and informativeness. To measure the efficacy, an IF-MADM model that has been recently proposed, AHP and the TOPSIS approach, which are compensatory models for group MADM, are used to model and solve the same collective decision. Using non-parametric statistical tests for data analytics, a similarity confirmation method' is proposed for a pair-wise test. This is to determine whether the score vectors are similar. Score vectors are used to determine the final ordinal ranks and whose scales differ greatly for different MADM methods. Since the latter two MADM models are both trustworthy with a known range of applications, any similarity in the results verifies the efficacy of IF-MADM. Using this process, the applicability of IF-MADM modelling is demonstrated. The efficiency and informativeness are also benchmarked and justified in terms of the model's ability to produce a more informed decision. These results are of interest to practitioners for the selection and application of MADM models. Finally, the selection of a senior centre, which is a real group decision problem, is used to illustrate these. This extends the empirical application of IF-MADM, as relatively few studies practically compare issues for IF-MADM with those for other MADM models. The study also supports a rarely studied non-clinical healthcare decision that is relevant because there are many aging societies.
\end{abstract}

Keywords: group decision, multi-attribute decision-making, intuitionistic fuzzy number, multiple criteria analysis, operational research in health services, data-driven decision making.

JEL Classification: D70, D79, C44, I15, D81, C14.

\footnotetext{
${ }^{\star}$ Corresponding author. E-mail: schang@cycu.edu.tw
}

This is an Open Access article distributed under the terms of the Creative Commons Attribution License (http://creativecommons. $\mathrm{org} / \mathrm{licenses} / \mathrm{by} / 4.0 /$ ), which permits unrestricted use, distribution, and reproduction in any medium, provided the original author and source are credited. 


\section{Introduction}

\section{Background}

Multi-attribute decision-making (MADM), which is one of the two main fields in multi-criteria decision-making (MCDM) (Mardani et al., 2015; Zavadskas, Turskis, \& Kildienė, 2014), prioritizes and ranks the predetermined alternatives by assessing multiple alternative attributes. Complexity increases when there is more than one decision maker (DM), because the final decision must reach a consensus that can be at best agreed, or at least accepted by the stakeholders (i.e., the participants) from the interest group ( $\mathrm{Ma}, 2010)$. It has been recently shown that when there is uncertainty in the expression of information that is relevant to a decision in a human cognitive process, methods that use fuzzy set theory are suited to modelling (Li, Kou, Lin, Xu, \& Liao, 2015; Kahraman, 2008; Yang \& Madan, 1994) the solution to a group MADM problem (Tzeng \& Huang, 2011; Chen, C.-L. Hwang, \& F.-P. Hwang, 1992).

One of these approaches is the IF-MADM approach (Xu \& Yager, 2008), which uses the theory of intuitionistic fuzzy sets (IFS) and expresses the preferences of DMs in terms of intuitionistic fuzzy numbers (IFNs). In IF-MADM, IFN is used to investigate and determine (for a DM) whether an alternative has membership and non-membership with a specific criterion (attribute). These are then used to construct an IFN. The subsequent calculation (MADM model solution) process then uses such rough fuzzy reasoning logic.

IFNs that rely on the theory of IFS can be used to mine and determine the actual preference structure for a DM. However, although IFS is a mature system, when solving the practical decision problems, "many of these types of problems take advantage of the availability of imprecise inputs" (Velasquez \& Hester, 2013). Therefore, the use of IFS is subject to the decision context, where an 'imprecise input' is required and available. As this is also true for IF-MADM, before using the IF-MADM approach for decision modelling, a DM might be concerned about 1: how the decision-aid procedure will be altered if an IF-MADM model is used and 2: given the stipulated practical advantages of IF-MADM, whether an IF-MADM model is more effective than, or at least as effective as other common MADM models that have many empirical applications.

Therefore, a decision-aid process that uses IF-MADM must be analysed empirically, in order to benchmark and determine the effectiveness of IF-MADM modelling in practice. This is discussed in more detail later.

In this study, four dimensions are used to measure the effectiveness of IF-MADM for making a practical group decision: applicability, efficacy (Reinartz, Haenlein, \& Henseler, 2009), efficiency and informativeness. Sourcing real data and modelling a real group decision case with IF-MADM establishes confidence in the applicability of IF-MADM. The results of modelling the same problem using alternative MADM approaches are then compared. The similarities in the results (i.e., the main outputs and the sub-products for these models) determine the efficacy of the IF-MADM approach. By observing the solution processes for relevant models, the efficiency and informativeness of the IF-MADM approach are also determined. These address the concerns that are mentioned previously.

Using these guidelines, the IF-MADM model and the alternative MADM approach are selected. This study uses a model that has been recently proposed (Ye, 2013) as the IF-MADM 
model to be benchmarked. The reasons for this choice are discussed in detail in 1.2.3. A trustworthy (common in the literature and having a wide range of applications that support various real decisions) analytic hierarchy process (AHP) model is used as the main alternative approach. The technique for order preferences by similarity to an ideal solution (TOPSIS) model is used for a 'test of robustness', in order to validate the similarity between the results that are obtained using both models. These methods are reviewed in the literature review.

A group decision case is studied. This is a real decision problem that is sufficiently typical to illustrate the benchmarking process for IF-MADM. At best, by solving this problem for a new area, the range of applications for IF-MADM is increased and the field of study is enhanced by the new decision supporting functions (of the IF-MADM approach). This study uses a problem whereby a group of quasi-seniors must select a suitable senior centre as a shared residence after retirement.

\section{Literature study}

\section{The theory of Intuitionistic Fuzzy Sets (IFS)}

The theory of IFS is an extension of traditional fuzzy set theory. It is currently being developed and some recent studies show that it is a suitable basis for MCDM modelling, because it better expresses the membership of elements in a set. This is the advantage that an IFS provides for a DM.

In classical set theory, the membership of an element (i.e., the membership relationship between the element and the set) is bivalent. This relationship can be expressed as a binary variable (or a functional value $\in\{0,1\}$ ). To address the limitations of this expression format, fuzzy set theory (FST) was proposed (Zadeh, 1965) to allow a gradual assessment of the membership relation, which is expressed by a number in the interval $[0,1]$ or a function that has a value within this interval. However, this is still insufficient, because a DM's preferential structure statement can pertain to the non-membership of an element. Therefore, as an extension of the theory of traditional FST, the theory of IFS was proposed (Atanassov, 1986). This expresses the stated vagueness's: i.e., the degree of membership and non-membership of an element in a set. It addresses the problem of imperfect or imprecise information, in terms of the derived degree of hesitancy (Pankowska \& Wygralak, 2006). In other words, IFS is a general extension of the theory of fuzzy sets, but the latter is a general extension of the theory of classical sets. As such, when there are imprecise or not totally reliable judgments, IFS is especially useful (Gong, Xu, Yang, Zhou, \& Zhang, 2016). These advantages of IFS mean that it is a suitable expression format for understanding a DMs preferential structure in the various decision-making contexts that facilitates a truly precise decision.

Let $A$ be a subset of the universe $U$. An IFS, $A^{\prime}$, is defined as:

$$
A^{\prime}=\left\{\left\langle x, \mu_{A}(x), v_{A}(x)\right\rangle \mid x \in U, 0 \leq \mu_{A}(x)+v_{A}(x) \leq 1\right\},
$$

where $\mu_{A}(x)$ and $v_{A}(x)$ are respectively the membership and non-membership functions of $x$ that determine the degree of membership and non-membership for element $x$.

Define $\pi_{A}(x)$ as the degree of hesitancy for $x$, which is the degree of indeterminacy that remains unresolved, as:

$$
\pi_{A}(x) \mid \pi_{A}(x)=1-\left(\mu_{A}(x)+v_{A}(x)\right) .
$$


This allows an alternate expression of any tuple element in $A^{\prime}$, as:

$$
A^{\prime \prime}=\left\{\left\langle x, \mu_{A}(x), v_{A}(x), \pi_{A}(x)\right\rangle \mid x \in U, 0 \leq \mu_{A}(x)+v_{A}(x) \leq 1, \mu_{A}(x)+v_{A}(x)+\pi_{A}(x)=1\right\} .
$$

This expression format for the IFS elements is multi-dimensional and enables a $3 \mathrm{D}$ representation of each element. This mathematical property allows the similarity or distance to be measured, such as the spherical distance measure (Yang \& Chiclana, 2009) and its generalized version (Gong et al., 2016).

\section{Intuitionistic-fuzzy-based Multi-attribute Decision-making (IF-MADM)}

IFS has been combined with MCDM models. Gong et al. (2016) used the geometry-based spherical distances to construct a multi-objective decision-making (MODM) model for group decisions. The objective functions minimize the spherical distances between the IFS's. However, to the authors' best knowledge, there are relatively few studies of the applications of IF-MODM.

In terms of IF-MADM, there are empirical applications and it is used in practice for threat assessment, personnel promotion and supplier selection problems (Bali, Dagdeviren \& Gumus, 2015; Boran, Genç, \& Akay, 2011; Huang, Zhao, \& Li, 2012; Xu, Wang, \& Miu, 2012). Li (2005) developed several linear programming (LP) models for MADM problems, using IFS's to obtain the optimal weights for attributes. Atanassov, Pasi, and Yager (2005) discussed the IF interpretations of multi-person and multi-measurement tool to make multi-criteria decisions. Lin, Yuan, and Xia (2007) proposed a model that expresses the satisfiability and non-satisfiability of the alternatives in terms of IFS's. Vlachos and Sergiadis (2007) utilised the concepts of discrimination information and cross-entropy in the IF setting and information-driven measures to compare sets were established. F. E. Boran, K. Boran, and Menlik (2012) applied IF-based TOPSIS to evaluate renewable energy technologies. Ouyang and Pedrycz (2016) proposed a new IF-MADM model which can deal with the degree of membership and the degree of non-membership separately. Oztaysi, Onar, Kahraman, and Yavuz (2017) developed an interval-valued IF-MADM method for the selection of vehicles that use alternative fuels.

Except for making 'non-group' decisions, IF-MADM is applicable to group decision-making. This can be traced from the earlier methodological works. Szmidt and Kacprzyk (1996) applied IFS's to group decision-making in order to derive some solution concepts. Xu (2007) investigated IF preference relations and their applications in group decision-making using an 'ordered weighted averaging' (OWA) operator. Bayrak, Çelebi, and Taşkin (2007) presented an algorithm for fuzzy group MADM for supplier selection problems wherein the relevant steps were defined. However, the study utilized traditional fuzzy sets. Boran, Genç, Kurt, and Akay (2009) applied IF-based TOPSIS to make a group supplier selection decision. Li, Chen, and Huang (2010) proposed the use of MODM-based LP for group MADM using IFS's (i.e., group IF-MADM) to select doctoral students. Li and Nan (2011) employed TOPSIS to solve a group MADM problem under the IFS environment. Xu (2011) proposed a series of IF power aggregation operators and applied them to group MADM in the IVIF (interval-valued intuitionistic fuzzy) and non-IVIF contexts. Das, M. B. Kar, and S. Kar (2013) combined the concept of IFS and multi-FS to construct an intuitionistic multi-fuzzy set to diagnose heart 
disease. Therefore, to the authors' knowledge, one empirical application concerns a clinical healthcare decision.

In the reviewed literature, a watershed (for the IF-MADM works from methods to applications) occurred about a decade ago was a consequence of the methods being sufficiently well developed. However, the role of methodological studies of IF-MADM is still important. Making group decisions in different fields using IF-MADM makes a ground for its application to the problem of this study, especially since a clinical healthcare decision has already been studied. In this sense, the use of IF-MADM for a non-clinical healthcare decision is significant because the relevant applications are still limited. It widens the range of IF-MADM applications, and as such, this study also provides new supplementary methodological means to the destination field.

As stated previously, the IF-MADM model that was proposed by Ye in 2013 (Ye-IFN) is used as the IF-MADM model for this study (Ye, 2013). The model is designed to make group decisions and can be used with two types of data-investigation settings: non-IVIF IFN and IVIF IFN (Atanassov \& Gargov, 1989; Chen, Li, \& Wang, 2011; Li, 2005; Zhao, 2014; Ren \& Wang, 2015). This study uses the former setting because it is simple to implement.

Unlike the IF-MODM model, which uses a derived hesitancy function (as defined in Eq. (2)), this IF-MADM model uses a derived score function for an IFN element (Chen \& Tan, 1994; Huang et al., 2012), which is defined as:

$$
s_{A}(x) \mid s_{A}(x)=\mu_{A}(x)-v_{A}(x) .
$$

This gives another alternate expression for any tuple element in $A^{\prime}$, as:

$$
A^{\prime \prime \prime}=\left\{\left\langle x, \mu_{A}(x), v_{A}(x), s_{A}(x)\right\rangle \mid x \in U, 0 \leq \mu_{A}(x)+v_{A}(x) \leq 1, s_{A}(x)=\mu_{A}(x)-v_{A}(x)\right\} .
$$

Most MADM models prioritize and determine the order for a set of alternatives using a set of criteria (CS). If $x$ represents an alternative (i.e., $A l t_{i}$, where $i$ is the alternative index) and $A$ connotes a criterion (i.e., $C_{j}$, where $j$ is the criteria index), then in Eq. (5), the original membership and non-membership relationships for "whether $x$ belongs to or does not belong to a set $A$ " are translated as "whether $A l t_{i}$ fulfils (validated) or does not fulfil (non-validated) a criterion $C_{j}$ ”. Therefore, Eq. (5) is rewritten as follows:

$$
\begin{aligned}
A_{j}^{*}= & \left\{\left\langle A l t_{i}, \mu_{C_{j}}\left(A l t_{i}\right), v_{C_{j}}\left(A l t_{i}\right), s_{C_{j}}\left(A l t_{i}\right)\right\rangle \mid A l t_{i} \in U_{A l t},\right. \\
& \left.0 \leq \mu_{C_{j}}\left(A l t_{i}\right)+v_{C_{j}}\left(A l t_{i}\right) \leq 1, s_{C_{j}}\left(A l t_{i}\right)=\mu_{C_{j}}\left(A l t_{i}\right)-v_{C_{j}}\left(A l t_{i}\right)\right\}
\end{aligned}, \text { for all } C j \in C S .
$$

It is seen that if all of the degrees of membership and non-membership in Eq. (6) (i.e., $\mu_{C_{j}}\left(A l t_{i}\right)$ and $\left.v_{C_{j}}\left(A l t_{i}\right)\right)$ are not determined by functions, but are directly valued by the DM, then for each criterion $C_{j}$, there is a valued IFS for all alternatives, which is $A_{j}^{*}$. The value of the score function that represents the 'net preference' of a DM for alternative $i$ in terms of criterion $j, s_{C_{j}}\left(A l t_{i}\right)$, can then be measured.

This is relevant to subsequent MADM modelling, because a MADM model (e.g., TOPSIS, simple-additive-weighting (SAW), or the selected Ye-IFN model for IF-MADM) usually construct a decision matrix, $D$, as the basis for the later calculation stages. The rows of $D$ are the alternatives and the columns are the criteria. 
If $k$ is a superscript of the decision matrix, where $k$ is the DM index, then $D^{k}$ is defined as:

$$
D^{k}=\left[d_{i j}\right]_{(I \times J)}, i=1 \ldots I, j=1 \ldots J .
$$

In terms of the score-function-based IF-MADM model, such as the Ye-IFN model, the original IFN data format that is provided by each DM is:

$$
D^{k}=\left[\left(\mu_{C_{j}}\left(A l t_{i}\right), v_{C_{j}}\left(A l t_{i}\right)\right)\right]_{(I \times J)} \equiv\left[\left(\mu_{i j}, v_{i j}\right)\right], i=1 . . I, j=1 . . J .
$$

Methodologically speaking, using a single derived score function value as a decision matrix element in Eq. (7) gives data that is compatible with most MADM models. Using Eq. (4) and Eq. (6), Eq. (8) is transformed so that it no longer contains a paired element:

$$
S^{k}=\left[s_{i j}^{k}\right]_{(I \times J)}, i=1 \ldots I, j=1 \ldots J .
$$

This links IFS theory and IF-MADM so the Ye-IFN model is used because the model is designed for group IF-MADM and it uses the score function to assess the net preference of a DM, $S^{k}$, as to form $D^{k}$.

The Ye-IFN model also obeys the concept of information entropy (Shannon, 1948; Wei, Liang, Wang, \& Qian, 2013), so DM's do not have to specify much information initially, while part of which may be imprecise; i.e., neither the additional information that is used to assess the criterion weights ${ }^{1}$ nor the information to assess the opinion weights (of the DMs) is necessary. The inputs for the model are simply the IFN-based datasets (i.e., $D^{k}$ in Eq. (8) for each DM $k$ ). The real decision matrix, $S^{k}$, is easily derived and each element in $S^{k}$ contains a single value for a DM's net preference for each alternative in terms of a criterion. Similarly to other MADM models, the main output for the model is an ordinal rank, which is prioritized with reference to the final SAW score vector for the alternatives. This is the case for many other MADM models and provides the same output format for comparing the results, despite the fact that different MADM models produce score vectors with different scales. The model's solution process also automatically generates sub-products: the criterion weights and the opinion weights. Therefore, DMs can reach a more informed decision. However, this study also uses these sub-products to make other comparisons.

\footnotetext{
$\overline{1}$ To solve ranking/selection problems, many MADM models have an investigation step to source the data for the evaluation of the priority (weights) in terms of the decision factors (criteria or constructs) (i.e., the criteria weight vector, or CWV). Data about how each alternative performs in terms of a specific criterion (attribute) is collected, either from the DM directly or from the existing data sets or both. For example, for an AHP, a first stage data investigation is a survey that produces a pairwise comparison matrix to determine the relative importance of the criteria that the DM stipulates (to determine the value of the CWV), and a second stage data investigation is also conducted to obtain several pairwise comparison matrices, each of which applies to a specific criterion, to determine an alternatives suitability in comparison to others in terms of the criterion. The calculation process for the AHP then uses these two types of source data to obtain a score vector for the alternatives, and a final ranking order is determined. For the problem that is used in this study, each of the 3 DMs would undergo 6 rounds of questions to fill 1 matrix during the first stage and 5 matrices during the second, which is a total of 18 matrices for the source data. As with long pairwise comparisons some psychological limits of human brain do exist, this impacts the precision of the collected source data when making an AHP survey (Fernández \& Márquez, 2012; Márquez, 2007). In contrast, the discussed survey style for the IF-MADM approach involves only one stage of investigation and avoids these problems to some extent.
} 
The Ye-IFN IF-MADM model is classified as a compensational, ratio-scaled, group MADM model. Given the properties of this model, other 'trustworthy' group MADM models can be used as an alternative approach, because many other MADM models are compensational and ratio-scaled. They also support group decisions but have a wide range of applications in practice. This gives a fair and a meaningful basis for the comparisons. Therefore, this model is used for the IF-MADM approach in this study because the results can be reasonably compared with other widely used MADM models, such as AHP, SAW or TOPSIS, which have similar properties to MADM.

\section{AHP and TOPSIS: the trustworthy alternative approaches}

This study uses a trustworthy group MADM model as the main alternative approach. The AHP model (Saaty, 1977) is used because it is a common group MADM method that has been applied for decades. AHP allows a hierarchical organisation of the overall decision goal, the criteria and the sub-criteria, where the alternatives are placed in the bottom layer. A standard AHP has two phases: an initial phase that determines the weights for the criteria and a final phase that prioritises the alternatives. Its applications are detailed in, but not limited to, these recent articles: (Akka, Abu, Spearpoint, \& Giovinazzi, 2016; Bian, $\mathrm{Hu}$, \& Deng, 2017; Chi, Zhuang, Fu, \& Huang, 2018; Dong \& Cooper, 2016; Dweiri, Kumar, Khan, \& Jain, 2016; Erdogan, Šaparauskas, \& Turkis, 2017; Govindan, Kaliyan, Kannan, \& Haq, 2014; Hillerman, Souza, Reis, \& Carvalho, 2017; Nikou \& Mezei, 2014; Samuel, Asogbon, Sangaiah, Fang, \& Li, 2017). The application of AHP is popular and this is based on its efficacy, so the method is used to construct many hybrid models (Ho, Chang, \& Ku, 2013; Kokangül, Polat, \& Dağsuyu, 2017; Li, Yu, Pei, Zhao, \& Tian, 2017; Szulecka \& Zalazar, 2017). Recent studies have extended AHP using the concept of IFS’s (Xu \& Liao, 2014; Sadiq \& Tesfamariam, 2009). However, in these studies, AHP is used to establish hybrid models (using also IFS), but in this study it is used as the benchmarking target for IF-MADM. Anyhow, AHP is not only a valid alternative approach, but also a ratio-scaled, compensatory group MADM model, so it provides a solid and fair basis for comparisons.

For a 'test of robustness', the TOPSIS model, which was proposed after AHP, is used (Hwang \& Yoon, 1981; Hwang, Lai, \& Liu, 1993). In the MADM school of MCDM, it is also widely used (Bao, Ruan, Shen, Hermans, \& Janssens, 2012; Gupta \& Barua, 2017; Y. H. He, Wang, Z. Z. He, \& Xie, 2016; Kang, Jang, \& Park, 2016; Kannan, de Sousa Jabbour, \& Jabbour, 2014; Kuo, Wu, \& Hsu, 2012; Liu, Chan, \& Ran, 2013; Mahdevari, Shahriar, \& Esfahanipour, 2014; Mir et al., 2016; Walczak \& Rutkowswa, 2017; Wang \& Peng, 2015; Zhou, Liu, \& Chang, 2016). Other recent studies also extend TOPSIS with the concept of IFS's (Boran et al., 2009; Chen, 2015; J. H. Park, I. Y. Park, Kwun, \& Tan, 2011; Li, 2010; Wang \& Chen, 2017; Ye, 2010; Zhao, 2014). However, these studies use TOPSIS to establish hybrid models using IFS, too. But this study uses TOPSIS for the robustness test.

TOPSIS is one of the common methods, as: “... some other widely used methods (in addition to AHP) are the ELECTRE (ELimination Et Choix Traduisant la REalité) and TOPSIS methods" (Triantaphyllou, 2000; Govindan \& Jepsen, 2016). However, ELECTRE is a non-compensatory (outranking) method (Majumder, 2015), so TOPSIS is another alternative method for this study because all the three methods that are compared are compensatory 
models. In addition, ELECTRE requires an additional threshold and the ranking of the alternatives depends on the size of this threshold, for which there exists no 'correct' value (Sabaei, Erkoyuncu, \& Roy, 2015). It is also too different for the purpose of comparison, even though, "there is neither a strong reason to reject a particular school of MCDM (MADM) nor a convincing argument to give general preference to one of the many methods" (Hanne, 2013).

The choice of TOPSIS for 'testing the robustness' is reflected in the more specific field of fuzzy MADM studies. In the 'distance based MADM' model category of the field, there are more articles present in the literature for fuzzy TOPSIS than the other main stream, fuzzy VIKOR, in this category, which takes the 'compromise solution' concept (Yu, 1973; Opricovic \& Tzeng, 2004, 2007; Sayadi, Heydari, \& Shahanaghi, 2009; Zeleny, 2011; Liu, Tzeng, \& Lee, 2012; Zhang \& Wei, 2013; Sasanka \& Ravindra, 2015; Yazdani \& Payam, 2015). This can be observed further in terms of the 'cited times' metric of the most influential studies in each domain (Kahraman, Onar, \& Oztaysi, 2015).

\section{The studied case: the group decision problem for the selection of a senior centre}

The studied case involves a real-life group decision problem to select a preferred senior centre from some predetermined alternatives, using the opinions of several quasi-seniors. This is a typical group MADM problem because it involves the various attributes of senior centres and it takes the different opinions of DMs into account (i.e., problem-model fitness). The case also holds simplicity for illustration. The advantages of studying this problem are two-fold: 1) this is a key decision problem for many industrialized countries in which there are aging societies and 2) in the healthcare decision field, it is a new empirical problem.

Because advanced industrialized societies are growing older, societal-aging is a problem for almost all developed countries (Borji, 2016). Quasi-seniors have many choices for senior centres so the decision is increasingly important for citizens and governments, which control and manage the economy (Gruber \& Wise, 2001). Companies that profit from operating senior centres also benefit (Beisgen \& Kraitchman, 2003). A model-based support for making group decisions on the user side and the results of such a study are also relevant to governments and business entities that wish to understand the preference structures of quasi-senior DMs in terms of this decision, despite the regional limitations of the results. This is the economic driver that motivates the use of this problem for this study.

Empirical research uses observed and measured phenomena and derives knowledge from actual experience (PennState University Libraries, 2017), which is useful for social and social science studies (Bhattacherjee, 2012; Bryman, 2015) and business research (Bryman \& Bell, 2015). The notion of 'empirical research' has shifted over time away from the purely descriptive towards more sophisticated analytical studies (Frege, 2005). The merit of an empirical research usually requires a good, initial research question, which must be clear, comprehensible, researchable and connected with established research and theory (Dönmez, 2015).

As the studied decision involves a business problem (i.e., it relates to healthcare management), it is an illustrative example for empirical research. This empirical problem is not currently the subject of research so it is a valuable addition to the healthcare decision field and links with the established theories of MADM (including AHP, TOPSIS and the IF-MADM). The problem is novel for this field and contrasts with the well-studied clinical decisions that are already supported by DSS's, such as the IBM Watson (IBM, 2018), or other non-clinical 
decisions, such as nurse scheduling (Azaiez \& Al Sharif, 2005; Wang, Hsieh, Zhuang, \& Ou, 2014). This is also addressed in (Zhuang, Yang, Lee, \& Wang, 2018), but it concerns the issues that are involved in implementing DSS'. Even though the 'model base' for the mentioned DSS study is written in terms of IF-MADM, there is no theoretical reason for doing so, since the effectiveness of IF-MADM has not yet been determined. In this sense, this study also supports the implementation of DSS using IF-MADM.

\section{Organisation of this study}

Section 1 details the main experimental flow for this study, with formulations for each model given in a general form. The methodological contributions of this study, such as the use of a systematic flow to compare two or more MADM models (including a variety of measures to evaluate effectiveness) and the 'similarity confirmation method', are outlined. In Section 2, the group MADM decision case and the surveys are detailed. The case is modelled and solved using an IF-MADM model and the AHP. Section 3 compares the solution processes and the results from Section 2 and uses TOPSIS for a robustness test. The (SAW-ed) score vectors for (behind) the final ordinal ranks are compared using the proposed similarity confirmation method with non-parametric statistical tests. Conclusions are drawn at the end of this paper.

\section{Methodological process}

\subsection{For the survey}

Since each of the two models requires a different set of prescriptive source data, for each $\mathrm{DM}^{k}$ and $k=1 \ldots K$, where $K$ is the number of DMs, two separate surveys are conducted.

For the AHP-style survey, an expert questionnaire is designed. Using face-to-face interview, pair-wise comparison matrices are completed and calculations are made to determine the relative importance of each criterion (or construct) $\left(C_{j}\right.$, where $j=1 \ldots J$ and $J$ is as defined as in 1.2). A criterion weight vector $\left(C W V^{k}\right)$ is constructed and the initial consistency analysis for each respondent individual is performed (i.e., the CWV-determination phase for the process). If any consistency check using the consistent ratio (C.R.) fails, the DM is re-interviewed.

For the IFN-style survey, the same group of DMs are asked to express their source opinion data in terms of IFNs. This requires the design of an IFN-based questionnaire, wherein each cell contains two numbers that have non-interval values in the form of $\mu$ and $\nu$ (membership and non-membership) (i.e., $D^{k}=\left[\left(\mu_{C_{j}}\left(A l t_{i}\right), v_{C_{j}}\left(A l t_{i}\right)\right)\right]_{(I \times J)} \equiv\left[\mu_{i j}, v_{i j}\right], \forall k$, as defined in Eq. (8)). There is a special explanation of IFN before the questions are answered because the DMs have no experience of this type of questionnaire. Relevant paper profiles and the websites for the alternatives $\left(A l t_{i}, i=1 \ldots I\right.$, where $I$ is as defined previously) are then given (to allow a better understanding of these alternatives). The questionnaires are then answered and each yields a valued source decision matrix, $D^{k}$ (see also 1.2.2).

\footnotetext{
${ }^{2}$ It uses the prevalent MEAN architecture for SPA (single-page architecture) web development, constructs a No-SQL 'data base' (for the DSS) and utilises the R statistical platform to develop a 'model base' (for the DSS).
} 


\subsection{The modelling processes}

Using the two individual data sets from the surveys, the group decision problem is modelled and solved using AHP and the IF-MADM model that was proposed by Ye (2013). Figure 1 shows the flow for the modelling processes, which is also a guideline for the experiments in Section 3. For clarity, Figure 1 gives the size of the group MADM problem that is modelled later (i.e., $\left.P=\left(\left(D M_{k}, A l t_{i}, C_{j}\right) \mid k \in\{A, B, C\}, i=1 \ldots 4, j=1 \ldots 5\right)\right)$.

The initial phase of AHP requires human data to determine the CWV, but the alternative prioritization (and candidate selection) phase does not always require a standard pair-wise candidate evaluation process or other advanced selection methods, such as goal programming and recent extension models (Chang, Chen, \& Zhuang, 2012; Charnes, Cooper, \& Ferguson, 1955; Ho et al., 2013; Zhuang \& Hocine, 2018). As this phase is usually replaced by other MADM methods, subject to the successful acquisition of computer data (see also the recent literature that is reviewed in 1.2.3), this study uses the SAW method (sometimes named the weighted-sum method (WSM)). Table 1 (in the case modelling section) shows that there is an existing, well-organized data catalogue for the calculation of SAW for the studied case. It can also be used for the TOPSIS method that is used for the robustness test. In the initial CWV-determination phase, the standard AHP is enacted, in order to avoid any loss of generality, even though some studies improve the accuracy of this step (Hossain, Adnan, \& Hasin, 2014).

The following two subsections review the modelling processes individually. Experienced readers need not read these because Figure 1 should be self-explanatory.

\subsubsection{Modelling using AHP}

(a) Obtain the mean CWV and the normalized mean CWV for the decision group.

(i) Obtain a mean CWV by taking the geometrical mean of the associated elements in the CWVs $\left(C W V^{k}\right)$;

(ii) Normalize the mean CWV to obtain the normalized mean CWV, which is $W_{\mathrm{AHP}}$

(b) For each alternative, evaluate its performance vector.

(i) From the collected computer-based data, obtain the subtotal scores (which might $\geq 1)$ that are aggregated for all constructs $\left(C_{j}, j=1, \ldots, J\right)$, for each alternative Alt $_{i}$;

(ii) Obtain each alternatives's performance vector, $T_{A l t_{i}(1 \times J)}$, by aggregating the subtotal scores.

(c) Calculate a normalized performance matrix and the normalized performance scores (NPS) vector for each alternative. This initially gives a matrix, $\bar{T}_{(I \times J)}$, which contains the criterion-wise normalized scores for each alternative. Each row of $T$, which is denoted as $\bar{T}_{A l t_{i}}$, is the NPS vector for the $i$-th alternative. These are mathematically expressed as:

$$
\begin{aligned}
& T=\underset{i=1 \ldots I}{\otimes} T_{A l t_{i}}, \text { or } \operatorname{Row}(T, i)=T_{A l t_{i}} ; \\
& T_{C_{j}}=\operatorname{Col}(T, j) ; \\
& \bar{T}_{C_{j}}=\underset{[0,1]}{\operatorname{Norm}}\left(T_{C_{j}}\right) ; \\
& \bar{T}=\underset{j=1 \ldots J}{\oplus} \bar{T}_{C_{j}}, \text { or } \operatorname{Col}(\bar{T}, j)=\bar{T}_{C_{j}},
\end{aligned}
$$

where $\otimes$ and $\oplus$ are the row compilation operator and column compilation operator, respectively. 
a)
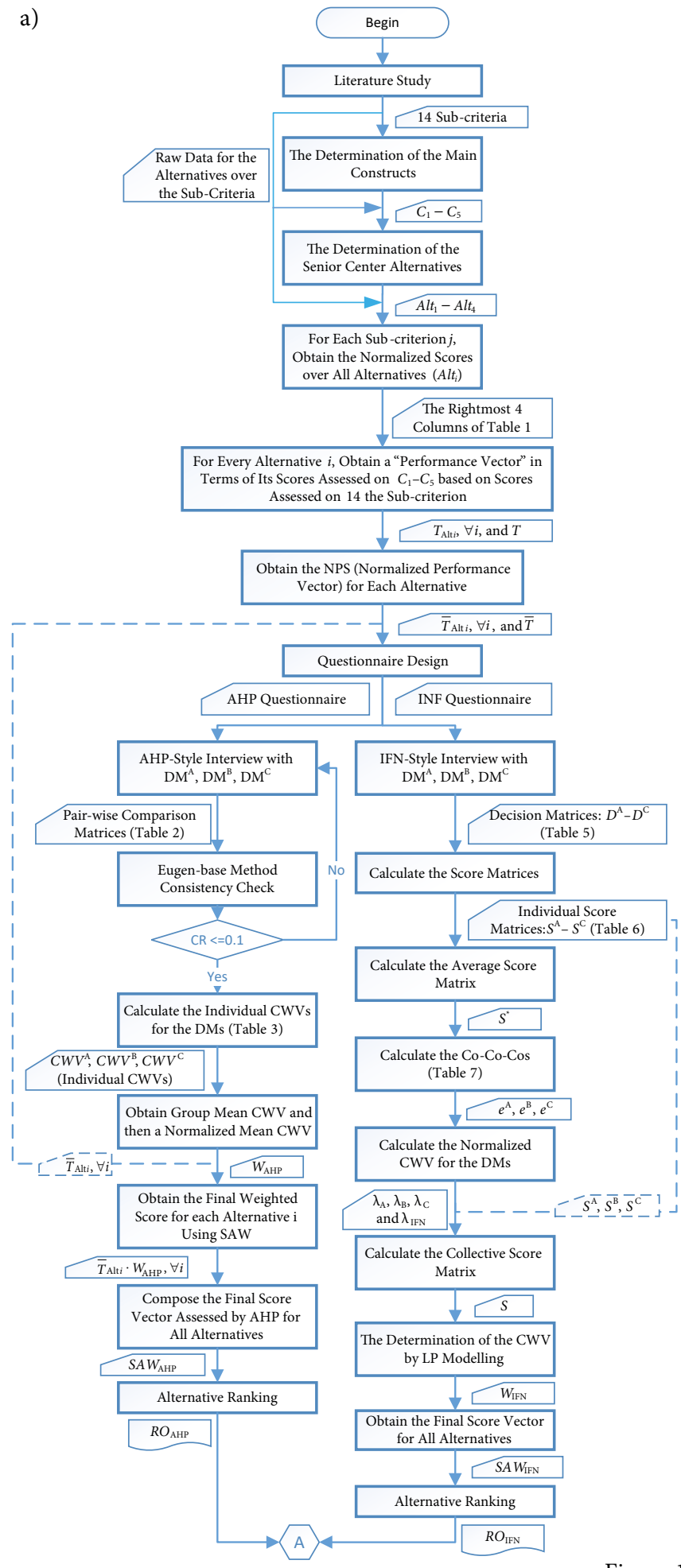

Figure 1. To be continued 


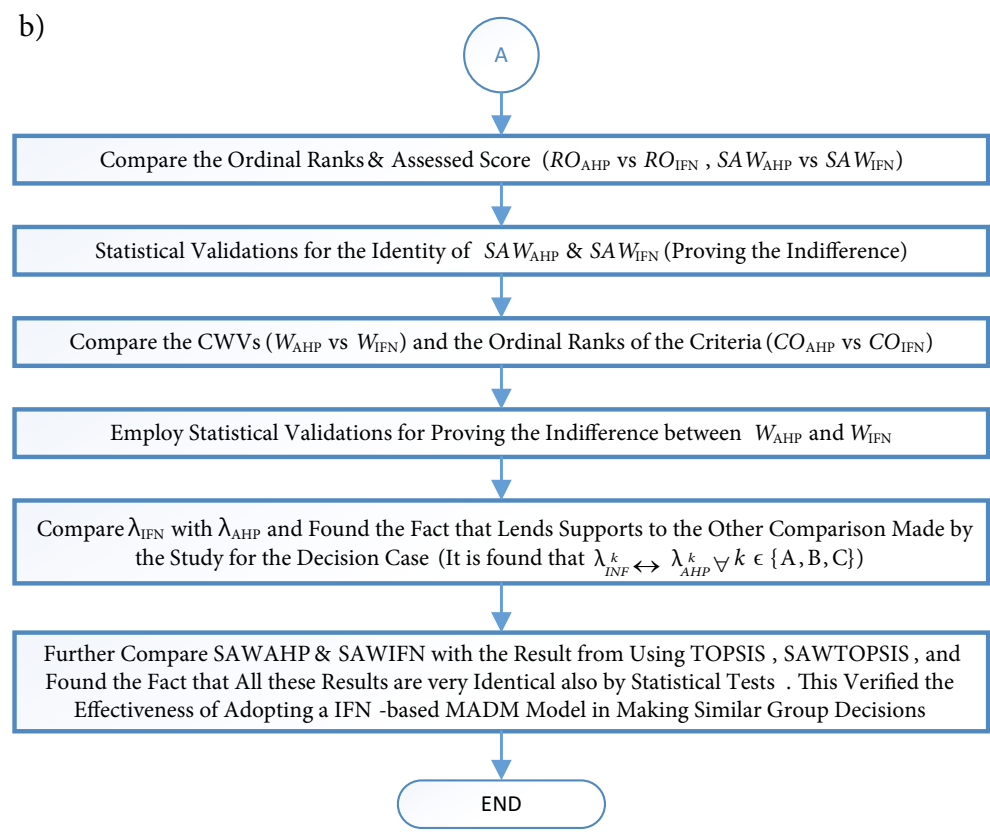

Figure 1. The experimental flow for this study: a - the flow for subsection 2.2; $\mathrm{b}$ - the flow for subsection 2.3

(d) Candidate evaluation and ranking.

(i) Given the NPS vector for each alternative $\left(\bar{T}_{A l t_{i}}\right)$ and the CWV, $W_{\text {AHP }}$ SAW can be used directly to give a final weighted score for the $i$-th alternative as:

$$
\bar{T}_{A l t_{i}(1 \times J)} \cdot W_{\mathrm{AHP}(J \times 1)} \cdot
$$

For all alternatives $(i=1, \ldots, I)$, this process can be simplified to obtain a final score vector, as:

$$
S A W_{\mathrm{AHP}}=\bar{T} \cdot W_{\mathrm{AHP}} \cdot
$$

(ii) Finally, the final ordinal rank, $R O_{\mathrm{AHP}}$ is obtained using the $S A W_{\mathrm{AHP}}$ vector.

\subsubsection{Modelling process using IF-MADM in terms of the Ye-IFN model}

(a) Calculate the score matrices for the DMs, the average score matrix and the collective correlation coefficients for the DMs (with reference to the average).

(i) Compute $S^{k}$ for each DM (i.e., the score matrices) from $D^{k}$ (the decision matrices in 2.1) using Eq. (6) and Eq. (8);

(ii) Calculate $S^{*}$ (the average score matrix, which represents the averaged opinion) from all the obtained values for $S^{k}$. The arithmetic mean can be used as:

$$
S^{*}=\left(\sum_{k=1 . . K} S_{k}\right) / K \text {. }
$$


(iii) Calculate the collective correlation coefficients (the Co-Co-Cos for the individual opinions) with respect to the average; i.e., $e^{k}$, for every $k$. Each of these measures the distance from a DMs opinion, $S^{k}$, to the average opinion, $S^{*}$ :

$$
e^{k}=\sum_{i=1}^{I}\left(\sum_{j=1}^{J} s_{i j}^{k} s_{i j}^{*} / \sqrt{\sum_{j=1}^{J}\left(s_{i j}^{k}\right)^{2}} \sqrt{\sum_{j=1}^{J}\left(s_{i j}^{*}\right)^{2}}\right),
$$

where $s_{i j}^{k}$ are the elements of $S^{k}$ as defined in Eq. (9).

(b) Obtain the normalized opinion weight vector (OWV) and the collective score matrix.

(i) The Co-Co-Cos are used to calculate the weight of an opinion for each DM, as:

$$
\lambda^{k}=e^{k} / \sum_{k=1}^{K} e^{k}
$$

Using this information, a normalized OWV is constructed, which is:

where $\lambda^{A}, \lambda^{B}$ and $\lambda^{C}$ are scalars.

$$
\lambda_{\mathrm{IFN}}=\left[\begin{array}{c}
\lambda^{1} \\
\lambda^{2} \\
\vdots \\
\lambda^{K}
\end{array}\right],
$$

The reasoning for this is that the distance from an opinion to the average opinion denotes the importance of the opinion, so if the $k$-th DM's opinion is closer to the distribution centre, his/her opinion must be assigned a heavier weight to $\lambda^{k}$.

(ii) When the weights of the opinion for the DMs are obtained, a collective score matrix, $S$, is obtained by applying these weights to the individual score matrices and then aggregating the results, as follows:

$$
S=\sum_{k} \lambda^{k} S^{k}
$$

(c) Determining the $C W V$. To determine the CWV, elements of $S$ are input into a LP model as the model parameters for its objective function, as follows:

$$
\begin{gathered}
\operatorname{Max} \sum_{i=1}^{I} \sum_{j=1}^{J} s_{i j} w_{j} \\
\text { s.t. } \sum_{j} w_{j}=1 \\
w_{j} \in I .
\end{gathered}
$$

In this model, the decision variables, $w_{j}$, represent the weights of the criteria $\left(C_{j}\right)$. The model has a constraint for weight postulation in that all weights must sum to 1 . It also incorporates a constraint list that limits the possible ranges of $w_{j}$, which is expressed as $I$. Therefore, the optimal CWV, $W_{\operatorname{IFN}(J \times 1)}$, is obtained by solving this model. Although in the literature there are revisions to this step, such as the use of AHP to assess the required CWV (Zhuang et al., 2018), this study uses the original version for this step to enact 'true IF-MADM' because by doing so, the result is relevant to the IFN's. 
(d) Evaluation and ranking of candidates.

(i) The SAW-ed final score for each $i$-th alternative, $A l t_{i}$, is obtained by multiplying the elements in the $i$-th row of $S_{(I \times J)}$ (i.e., $\left.\operatorname{Row}(S, i)\right)$ by the elements in $W_{\text {IFN }}$ and summing them. For all alternatives, this process can be simplified to obtain the final score vector as follows:

$$
S A W_{\text {IFN }}=S \cdot W_{\text {IFN }}
$$

(ii) Finally, another ordinal rank, $R O_{\mathrm{IFN}}$, is obtained from $S A W_{\mathrm{IFN}}$.

\subsection{Comparisons and the similarity confirmation method}

The results from the processes in 2.2 are compared and further analysis is performed. The observable benchmarking targets of interest that measure the efficacy are summarized as follows:

- The final ordinal ranks. The final rank orders, $R O_{\mathrm{AHP}}$ and $R O_{\mathrm{IFN}}$, which are the final outputs for both models, are compared to determine whether they are similar (or even identical). In either case (similar or identical), other methods can be used to confirm any similarity. The first method is to use non-parametric statistical tests for $S A W_{\mathrm{AHP}}$ and $S A W_{\text {IFN }}$, in order to determine whether the score vectors that are used to determine the ordinal ranks are also similar. These form the proposed 'similarity confirmation method', which is discussed in 2.3.1. The second method is a robustness test that cross-validates the outcomes with those from other trustworthy MADM models. In this study, the relative closeness index (RCI) vector that is obtained using TOPSIS is used as a (SAW) score vector for comparison for the reasons that are detailed in 1.2.3.

- The CWVs. The two CWVs, $W_{\mathrm{AHP}}$ and $W_{\mathrm{IFN}}$ are the sub-products of both models and these are also checked to determine whether they agree with each other.

- The OWVs. The OWV is also a sub-product of the IF-MADM model (i.e., $\lambda_{\text {IFN }}$ ), but not a sub-product of AHP. However, the standard AHP approach applies equal opinion weights. These equal weights form a virtual OWV, which is denoted as $\lambda_{\mathrm{AHP}}$. If $\lambda_{\text {IFN }}$ concurs with $\lambda_{\mathrm{AHP}}$ the results of this study are salient. Therefore, the consistency of these two OWVs is also of interest.

The logic behind these comparisons is: if AHP is efficacious, the IF-MADM approach is also efficacious, if the final decisions and the sub-products are similar when they are used to solve the same group MADM problem ${ }^{3}$.

With the exception of determining the efficacy of the IF-MADM model, the applicability of which is confirmed if one such IF-MADM model can be successfully applied to support the real group decision case empirically. As well as these processes, time measures are established to benchmark the efficiency of the models. The outputs for each solution process are used to determine whether the compared model is informative. As such, except for the

\footnotetext{
${ }^{3}$ Usually, for MADM modeling, the solution process can be viewed as a computer-aided box if only the final output (i.e., the rank order) is of interest. But if not only the final ordinal ranks but also the score vectors that are obtained separately are similar and this can be further confirmed by using the similarity confirmation method, the IF-MADM approach is said to be efficacious. If their sub-products also concur with each other, the efficacy of the IF-MADM is further increased. In other words, should these be the outcome, the efficacy of AHP can be used to verify the efficacy of the IF-MADM.
} 
statistical-based similarity confirmation method that is discussed hereafter, the comprehensive multi-dimensional measuring framework that is proposed to benchmark two or more MADM models represents another methodological contribution. The advantages of these methods are demonstrated by modelling an empirical case in the next section.

\subsubsection{The 'similarity confirmation method'}

As discussed previously, in this study, except for the observations of the direct outputs of the MADM models (i.e., the final ordinal ranks), non-parametric statistical tests are employed to determine the similarity between the score vectors, in order to confirm the observations based on the ordinal ranks (e.g., similar or identical). This verifies the efficacy of the IFMADM approach. This similarity confirmation process is important because situations arise whereby the ordinal ranks are similar or even identical, but in fact the score vectors that are actually used to determine these ranks are different, such as when they are statistically justified, come from non-identical populations or have different distributions.

The similarity confirmation method involves the following steps:

Step 1: Observe whether there is any similarity between the final rank orders (or if they are identical) by using two MADM approaches to solve the same empirical group decision (e.g., by calculating the difference in rank according to the absolute difference vector for the two rank order vectors). If there is similarity, go to step 2;

Step 2: Treat the elements in the two score vectors (obtained using the two MADM approaches) that are used to determine the final ordinal ranks as two samples and standardise them, in order to de-scale and eliminate the incommensurability between them;

Step 3: Use the non-parametric paired signed-rank test to determine whether there is statistical evidence that the two score vectors are (from) non-identical populations. If they are not and there is little evidence (i.e., the $p$ value significantly exceeds the threshold, i.e. $>>0.1$ ) to justify that they are, it is very probable these two vectors are (from) an identical population and that the observed (and claimed) similarity in step 1 can be confirmed;

Step 4: Use the non-parametric two-sample Kolmogorov-Smirnov test with the two score vectors as the samples (the empirical distribution functions for the two samples), in order to determine whether they are non-identical distributions. If they are not and there is little evidence (i.e., the $p$ value significantly exceeds the threshold, i.e. $>>0.1$ ) to justify that they are, it is very probable that they are from an identical distribution and the observed (and claimed) similarity in step 1 can be further confirmed.

For this similarity confirmation method, when any similarity between the final ordinal ranks is observed, the two score vectors that are obtained individually using the two MADM methods are treated as statistical samples. These samples are standardised in step 2, and this eliminates the incommensurability in scales when different MADM methods are used to assess the score vectors and provides a commensurable data format for the subsequent steps that use the two-sample non-parametric statistical tests. Note that the 'standardisation' process has a statistical basis so it is intrinsically different to any 'normalisation' process in terms of the operational research thought. 
Usually, in statistics or data analytics, non-parametric tests are used when the population is unknown or cannot be presumed. The similarity confirmation method uses them to determine whether two score vectors are from an identical population and/or have an identical distribution, in order to confirm the similarity between the final ranks, which is directly observable. Given the specific context of any real MADM problem, neither the rank of the alternatives nor the scores that are assessed to produce this rank is presumable. The two-sample non-parametric tests are convenient tools for statistically determining whether two variable samples are from non-identical populations and whether they are drawn from non-identical distributions. Therefore, they can be used to check whether two score vectors that are obtained using two different MADM methods for the same MADM problem are dissimilar or not (i.e., similar), subject to the context in which the population and the distribution of the elements in the (SAW) score vectors cannot be presumed. In other words, if it cannot be asserted that two score vectors are from non-identical populations and are from non-identical distributions and there is little evidence to support these suppositions ( $p>>0.05$ for both tests), the observed similarity in the final ordinal ranks can be confirmed by reference to these facts.

Comparing this similarity confirmation method with the spherical distance method (see 1.2.1) gives further understanding of its purpose. Methodologically, the latter is a geometrical method and the former is statistically based. In terms of the application contexts, the data input for the latter are the membership, the non-membership and the derived hesitancy degrees (which form a tuple element of an IFS, i.e., Eq. (3)). However, the inputs for the former are the score vectors that are used to determine the final ordinal ranks (such as Eq. (12) or Eq. (19)), which are the results for a MADM model. Finally, the similarity (distance) measurement targets for these two methods are also different. The latter measures the distance between two IFN's or IFS's, but the former measures whether two score vectors can render any evidence to support the observed similarity between the final ordinal ranks, one of which may use the IF-MADM method.

\section{Modelling and solving the group decision example}

\subsection{Case description, data investigation and surveys}

The setting for the studied empirical problem consists of a decision group of three quasisenior DMs ( $\left.\mathrm{DM}^{k}, k \in\{\mathrm{A}, \mathrm{B}, \mathrm{C}\}\right)$ who must choose a senior centre from four possible alternatives as a shared residence after retirement $\left(A l t_{i}, i=1, . ., 4\right)$. The five constructs (main criteria) that pertain to the selection $\left(C_{j}, j=1, \ldots, 5\right)$ are used. The size of this group decision problem is: $P=\left(\left(D M_{k}, A l t_{i}, C_{j}\right) \mid k \in\{A, B, C\}, i=1 \ldots 4, j=1 \ldots 5\right)$.

According to 1.1, each model requires a heterogeneous set of prescriptive data at the survey stage so two types of survey are conducted using the same group of DMs, along with faceto-face interviews. The descriptions of this decision are detailed as supplementary material in Appendix A. The data that is sourced individually from each DM using the IFN-style and the AHP-style surveys is shown later, but the existing data catalogue that is used to calculate the SAW (which replaces the second phase of AHP; see the discussions in 1.2) is detailed. 
For the criteria set $\left(\left\{C_{j} \mid j=1 . .5\right\}\right)$ and the alternative set $\left(\left\{A l t_{i} \mid i=1 . .4\right\}\right)$ for the decision case, an investigative report is used. Please see Appendix B for more detail. Using this report, the parameters for the alternatives (i.e., the senior centres) are detailed (for the $14 \mathrm{sub}$ criteria) in the middle columns of Table 1. Constructing these columns also involves suitable nominal/cardinal conversions and bipolar linearization, the details of which are presented in Appendix C. The right part of Table 1 shows the 'by-sub-criterion normalized scores after geometric normalization' for each alternative.

Table 1 . The sub-criteria source data and the normalized scores for the alternatives

\begin{tabular}{|c|c|c|c|c|c|c|c|c|c|}
\hline \multicolumn{2}{|c|}{ Criterions (leveled) } & \multicolumn{4}{|c|}{ Source Data } & \multicolumn{4}{|c|}{ Normalized Scores } \\
\hline Criteria & $\begin{array}{c}\text { Sub-criteria } \\
\text { (Decision factor) }\end{array}$ & $A l t_{1}$ & $\mathrm{Alt}_{2}$ & $\mathrm{Alt}_{3}$ & $\mathrm{Alt}_{4}$ & $A l t_{1}$ & $\mathrm{Alt}_{2}$ & $\mathrm{Alt}_{3}$ & $A l t_{4}$ \\
\hline \multirow{2}{*}{$\begin{array}{l}C_{1}: \\
\text { Finance } \\
\text { Concerns }\end{array}$} & $\begin{array}{l}\text { 1. Price (NT\$/ } \\
\text { month) }\end{array}$ & 20900 & 19000 & 16000 & 12800 & 0.40106 & 0.45551 & 0.54148 & 0.63318 \\
\hline & $\begin{array}{l}\text { 2. Supporting } \\
\text { functions (Score) }\end{array}$ & 50 & 0 & 50 & 0 & 0.70711 & 0 & 0.70711 & 0 \\
\hline \multirow{4}{*}{$\begin{array}{l}C_{2} \text { : } \\
\text { Environment } \\
\text { Conditions }\end{array}$} & $\begin{array}{l}\text { 3. Neatness } \\
\text { (Score) }\end{array}$ & 100 & 100 & 100 & 100 & 0.5 & 0.5 & 0.5 & 0.5 \\
\hline & $\begin{array}{l}\text { 4. Use space } \\
\text { (Tsubo /Room- } \\
\text { bed) }\end{array}$ & 30 & 16 & 22 & 23.17 & 0.64299 & 0.34293 & 0.47153 & 0.49661 \\
\hline & 5. Safety (Score) & 100 & 80 & 80 & 80 & 0.58521 & 0.46816 & 0.46816 & 0.46816 \\
\hline & $\begin{array}{l}\text { 6. Residents / } \\
\text { bedroom (Score) }\end{array}$ & 50 & 75 & 50 & 50 & 0.43644 & 0.65465 & 0.43644 & 0.43644 \\
\hline \multirow{3}{*}{$\begin{array}{l}C_{3}: \\
\text { Facilities }\end{array}$} & $\begin{array}{l}\text { 7. Ventilation / } \\
\text { light (Score) }\end{array}$ & 100 & 100 & 100 & 100 & 0.5 & 0.5 & 0.5 & 0.5 \\
\hline & $\begin{array}{l}\text { 8. In-room } \\
\text { facilities (Score) }\end{array}$ & 83 & 83 & 100 & 67 & 0.49367 & 0.49367 & 0.59479 & 0.39851 \\
\hline & $\begin{array}{l}\text { 9. Leisure / } \\
\text { entertainment } \\
\text { (Score) }\end{array}$ & 86 & 100 & 71 & 86 & 0.49791 & 0.57896 & 0.41106 & 0.49791 \\
\hline \multirow{3}{*}{$\begin{array}{l}C_{4}: \\
\text { Service } \\
\text { Level }\end{array}$} & $\begin{array}{l}\text { 10. Healthcare } \\
\text { (Score) }\end{array}$ & 100 & 100 & 60 & 80 & 0.57735 & 0.57735 & 0.34641 & 0.46188 \\
\hline & $\begin{array}{l}\text { 11. Staff Service } \\
\text { (Score) }\end{array}$ & 100 & 100 & 83 & 83 & 0.54411 & 0.54411 & 0.45161 & 0.45161 \\
\hline & 12. Foods (Score) & 75 & 75 & 100 & 50 & 0.48666 & 0.48666 & 0.64889 & 0.32444 \\
\hline \multirow{2}{*}{$\begin{array}{l}C_{5}: \\
\text { Convenience }\end{array}$} & $\begin{array}{l}13 . \\
\text { Transportation } \\
\text { (Score) }\end{array}$ & 75 & 100 & 100 & 50 & 0.44721 & 0.59628 & 0.59628 & 0.29814 \\
\hline & $\begin{array}{l}\text { 14. Living } \\
\text { functions (Score) }\end{array}$ & 100 & 80 & 100 & 100 & 0.52414 & 0.41931 & 0.52414 & 0.52414 \\
\hline
\end{tabular}

Note: 1) The first sub-criteria are cost criteria but others are not; 2) For simplicity, the precision of the normalized outputs is set to $\left.10^{-5} ; 3\right)$ The data that is originally nominal is expressed cardinally; e.g., the in-room facilities score data for the \#1 senior centre, 83, is read from (and calculated based on) the fact that this senior centre offers 5 of 6 types of in-room facilities. 
For the AHP-style survey (1.1), Table 2 shows the pair-wise comparison matrices for the DMs, all of which have passed the consistency checks. It is worthy of note that the survey uses a 9-point-scale and that $\mathrm{DM}_{\mathrm{B}}$ was re-interviewed twice (to achieve C.R. validation).

Table 2. Source data from the AHP-style survey

a) AHP source data from $\mathrm{DM}_{\mathrm{A}}$

\begin{tabular}{|c|c|c|c|c|c|}
\hline $\mathrm{DM}_{\mathrm{A}}$ & $C_{1}$ & $C_{2}$ & $C_{3}$ & $C_{4}$ & $C_{5}$ \\
\hline$C_{1}$ & 1 & 3 & 3 & 3 & 3 \\
\hline$C_{2}$ & 0.333 & 1 & 1 & 1 & 3 \\
\hline$C_{3}$ & 0.333 & 1 & 1 & 1 & 3 \\
\hline$C_{4}$ & 0.333 & 1 & 1 & 1 & 3 \\
\hline$C_{5}$ & 0.333 & 0.2 & 0.333 & 0.333 & 1 \\
\hline Sum & 2.333 & 6.2 & 6.333 & 6.333 & 13 \\
\hline
\end{tabular}

b) AHP source data from $\mathrm{DM}_{\mathrm{B}}$

\begin{tabular}{|c|c|c|c|c|c|}
\hline $\mathrm{DM}_{\mathrm{B}}$ & $C_{1}$ & $C_{2}$ & $C_{3}$ & $C_{4}$ & $C_{5}$ \\
\hline$C_{1}$ & 1 & 0.5 & 0.5 & 1 & 3 \\
\hline$C_{2}$ & 2 & 1 & 2 & 3 & 4 \\
\hline$C_{3}$ & 2 & 0.5 & 1 & 3 & 4 \\
\hline$C_{4}$ & 1 & 0.333 & 0.333 & 1 & 7 \\
\hline$C_{5}$ & 0.333 & 0.25 & 0.25 & 0.143 & 1 \\
\hline Sum & 6.333 & 2.583 & 4.083 & 8.143 & 19 \\
\hline
\end{tabular}

c) AHP source data from $\mathrm{DM}_{\mathrm{C}}$

\begin{tabular}{|c|c|c|c|c|c|}
\hline $\mathrm{DM}_{\mathrm{C}}$ & $C_{1}$ & $C_{2}$ & $C_{3}$ & $C_{4}$ & $C_{5}$ \\
\hline$C_{1}$ & 1 & 3 & 6 & 2 & 7 \\
\hline$C_{2}$ & 0.333 & 1 & 2 & 0.3333 & 6 \\
\hline$C_{3}$ & 0.167 & 0.5 & 1 & 0.5 & 3 \\
\hline$C_{4}$ & 0.5 & 3 & 2 & 1 & 9 \\
\hline$C_{5}$ & 0.143 & 0.167 & 0.333 & 0.1111 & 1 \\
\hline Sum & 2.143 & 7.667 & 11.333 & 3.944 & 26 \\
\hline
\end{tabular}

The decision matrices for the IFN-based survey in the second interview (see 1.1) are shown in Table 3. It is again noted that $\mu_{i j}$ is the membership evaluation for the intensity with which $A l t_{i}$ fulfils $C_{j}^{\prime}$ and $v_{i j}$ is the non-membership evaluation for 'the intensity with which $A l t_{i}$ does not fulfil $C_{j}$ ' (see its definition Eq. (8)). During the interview, a DM was asked to look at the relevant profiles and websites for the alternatives and the investigative report is also given (i.e., the middle columns in Table 1) to clarify the judgments. Following this, the DM was shown a brief illustration of an IFN-style survey (to clarify the meaning of the two cells for each element; see 1.1) and then asked to complete a questionnaire in the format that is shown in Table 3. 
Table 3. Source data from the IFN-style survey

a) $D^{\mathrm{A}}$, assessed by $\mathrm{DM}^{\mathrm{A}}$

\begin{tabular}{|c|c|c|c|c|c|c|c|c|c|c|}
\hline \multirow{2}{*}{$\begin{array}{c}\text { IFNs of } \\
\mathrm{DM}_{\mathrm{A}}\end{array}$} & \multicolumn{2}{|c|}{$C_{1}$} & \multicolumn{2}{c|}{$C_{2}$} & \multicolumn{2}{c|}{$C_{3}$} & \multicolumn{2}{|c|}{$C_{4}$} & \multicolumn{2}{c|}{$C_{5}$} \\
\cline { 2 - 13 } & $\mu_{i j}$ & $v_{i j}$ & $\mu_{i j}$ & $v_{i j}$ & $\mu_{i j}$ & $v_{i j}$ & $\mu_{i j}$ & $v_{i j}$ & $\mu_{i j}$ & $v_{i j}$ \\
\hline$A l t_{1}$ & 0.2 & 0.75 & 0.78 & 0.12 & 0.7 & 0.15 & 0.6 & 0.25 & 0.7 & 0.15 \\
\hline$A l t_{2}$ & 0.2 & 0.7 & 0.7 & 0.3 & 0.6 & 0.3 & 0.7 & 0.2 & 0.6 & 0.3 \\
\hline$A l t_{3}$ & 0.1 & 0.8 & 0.7 & 0.2 & 0.8 & 0.1 & 0.7 & 0.2 & 0.4 & 0.5 \\
\hline$A l t_{4}$ & 0.2 & 0.7 & 0.5 & 0.4 & 0.7 & 0.2 & 0.6 & 0.3 & 0.3 & 0.6 \\
\hline
\end{tabular}

b) $D^{\mathrm{B}}$, assessed by $\mathrm{DM}^{\mathrm{B}}$

\begin{tabular}{|c|c|c|c|c|c|c|c|c|c|c|}
\hline \multirow{2}{*}{$\begin{array}{c}\text { IFNs of } \\
\mathrm{DM}_{\mathrm{B}}\end{array}$} & \multicolumn{2}{|c|}{$C_{1}$} & \multicolumn{2}{c|}{$C_{2}$} & \multicolumn{2}{c|}{$C_{3}$} & \multicolumn{3}{c|}{$C_{4}$} & \multicolumn{2}{c|}{$C_{5}$} \\
\cline { 2 - 12 } & $\mu_{i j}$ & $v_{i j}$ & $\mu_{i j}$ & $v_{i j}$ & $\mu_{i j}$ & $v_{i j}$ & $\mu_{i j}$ & $v_{i j}$ & $\mu_{i j}$ & $v_{i j}$ \\
\hline$A l t_{1}$ & 0.4 & 0.5 & 0.2 & 0.4 & 0.4 & 0.3 & 0.6 & 0.3 & 0.4 & 0.5 \\
\hline$A l t_{2}$ & 0.2 & 0.7 & 0.3 & 0.4 & 0.5 & 0.1 & 0.7 & 0.1 & 0.4 & 0.2 \\
\hline$A l t_{3}$ & 0.1 & 0.6 & 0.5 & 0.4 & 0.6 & 0.2 & 0.7 & 0.1 & 0.4 & 0.1 \\
\hline Alt $_{4}$ & 0.2 & 0.4 & 0.3 & 0.1 & 0.4 & 0.2 & 0.1 & 0.5 & 0.1 & 0.6 \\
\hline
\end{tabular}

c) $D^{\mathrm{C}}$, assessed by $\mathrm{DM}^{\mathrm{C}}$

\begin{tabular}{|c|c|c|c|c|c|c|c|c|c|c|}
\hline \multirow{2}{*}{$\begin{array}{c}\text { IFNs of } \\
\mathrm{DM}_{\mathrm{C}}\end{array}$} & \multicolumn{2}{|c|}{$C_{1}$} & \multicolumn{2}{c|}{$C_{2}$} & \multicolumn{2}{c|}{$C_{3}$} & \multicolumn{3}{c|}{$C_{4}$} & \multicolumn{2}{c|}{$C_{5}$} \\
\cline { 2 - 12 } & $\mu_{i j}$ & $v_{i j}$ & $\mu_{i j}$ & $v_{i j}$ & $\mu_{i j}$ & $v_{i j}$ & $\mu_{i j}$ & $v_{i j}$ & $\mu_{i j}$ & $v_{i j}$ \\
\hline$A l t_{1}$ & 0.3 & 0.5 & 0.6 & 0.3 & 0.7 & 0.2 & 0.6 & 0.2 & 0.5 & 0.4 \\
\hline$A l t_{2}$ & 0.3 & 0.6 & 0.5 & 0.4 & 0.5 & 0.2 & 0.8 & 0.1 & 0.5 & 0.3 \\
\hline$A l t_{3}$ & 0.6 & 0.3 & 0.6 & 0.3 & 0.5 & 0.3 & 0.3 & 0.4 & 0.4 & 0.5 \\
\hline$A l t_{4}$ & 0.1 & 0.6 & 0.4 & 0.3 & 0.6 & 0.3 & 0.3 & 0.5 & 0.3 & 0.5 \\
\hline
\end{tabular}

\subsection{Solving using AHP}

Using the information in Table 2, the individual CWVs for the DMs are determined in Tables 4(a), 4(b) and 4(c).

Table 4. CWVs for the DMs and the normalized mean CWV

a) $\mathrm{CWV}$ of $\mathrm{DM}_{\mathrm{A}}$

\begin{tabular}{|c|c|c|c|c|c|c|}
\hline $\mathrm{DM}_{\mathrm{A}}$ & $C_{1}$ & $C_{2}$ & $C_{3}$ & $C_{4}$ & $C_{5}$ & CWV: $W_{\mathrm{AHP}}^{\mathrm{A}}$ \\
\hline$C_{1}$ & 0.429 & 0.484 & 0.474 & 0.474 & 0.231 & 0.41811 \\
\hline$C_{2}$ & 0.143 & 0.161 & 0.158 & 0.158 & 0.231 & 0.17014 \\
\hline$C_{3}$ & 0.143 & 0.161 & 0.158 & 0.158 & 0.231 & 0.17014 \\
\hline$C_{4}$ & 0.143 & 0.161 & 0.158 & 0.158 & 0.231 & 0.17014 \\
\hline$C_{5}$ & 0.143 & 0.032 & 0.053 & 0.053 & 0.077 & 0.07146 \\
\hline
\end{tabular}


b) $\mathrm{CWV}$ of $\mathrm{DM}_{\mathrm{B}}$

\begin{tabular}{|c|c|c|c|c|c|c|}
\hline $\mathrm{DM}_{\mathrm{B}}$ & $C_{1}$ & $C_{2}$ & $C_{3}$ & $C_{4}$ & $C_{5}$ & CWV: $W_{\mathrm{AHP}}^{\mathrm{B}}$ \\
\hline$C_{1}$ & 0.158 & 0.194 & 0.122 & 0.123 & 0.158 & 0.15092 \\
\hline$C_{2}$ & 0.316 & 0.387 & 0.490 & 0.368 & 0.211 & 0.35433 \\
\hline$C_{3}$ & 0.316 & 0.194 & 0.245 & 0.368 & 0.211 & 0.26664 \\
\hline$C_{4}$ & 0.158 & 0.129 & 0.082 & 0.123 & 0.368 & 0.17196 \\
\hline$C_{5}$ & 0.053 & 0.097 & 0.061 & 0.018 & 0.053 & 0.05616 \\
\hline
\end{tabular}

c) $\mathrm{CWV}$ of $\mathrm{DM}_{\mathrm{C}}$

\begin{tabular}{|c|c|c|c|c|c|c|}
\hline $\mathrm{DM}_{\mathrm{C}}$ & $C_{1}$ & $C_{2}$ & $C_{3}$ & $C_{4}$ & $C_{5}$ & CWV: $W_{\text {AHP }}^{\mathrm{C}}$ \\
\hline$C_{1}$ & 0.467 & 0.391 & 0.529 & 0.507 & 0.269 & 0.43273 \\
\hline$C_{2}$ & 0.156 & 0.130 & 0.176 & 0.085 & 0.231 & 0.15555 \\
\hline$C_{3}$ & 0.078 & 0.065 & 0.088 & 0.127 & 0.115 & 0.09468 \\
\hline$C_{4}$ & 0.233 & 0.391 & 0.176 & 0.254 & 0.346 & 0.28016 \\
\hline$C_{5}$ & 0.067 & 0.022 & 0.029 & 0.028 & 0.038 & 0.03689 \\
\hline
\end{tabular}

d) The normalized mean CWV

\begin{tabular}{|c|c|c|c|c|c|}
\hline $\begin{array}{c}\text { Individual Subjective } \\
\text { Weight Vectors }\end{array}$ & $\mathrm{DM}_{\mathrm{A}}$ & $\mathrm{DM}_{\mathrm{B}}$ & $\mathrm{DM}_{\mathrm{C}}$ & $\begin{array}{c}\text { Geometric } \\
\text { Mean }\end{array}$ & $\begin{array}{c}\text { Normalized mean } \\
\text { CWV: } W_{\mathrm{AHP}}\end{array}$ \\
\hline$w_{1}$ of $C_{1}$ & 0.41811 & 0.15092 & 0.43273 & 0.30113 & 0.32412 \\
\hline$w_{2}$ of $C_{2}$ & 0.17014 & 0.35433 & 0.15555 & 0.21088 & 0.22697 \\
\hline$w_{3}$ of $C_{3}$ & 0.17014 & 0.26664 & 0.09468 & 0.16255 & 0.17496 \\
\hline$w_{4}$ of $C_{4}$ & 0.17014 & 0.17196 & 0.28016 & 0.20162 & 0.21702 \\
\hline$w_{5}$ of $C_{5}$ & 0.07146 & 0.05616 & 0.03689 & 0.05290 & 0.05694 \\
\hline Postulation Check & 1 & 1 & 1 & & 1 \\
\hline
\end{tabular}

The calculation in Table 4(d) uses 1.2.1.a. Firstly, each mean CWV is obtained by taking the geometrical mean of the associated elements in the three CWVs (e.g., for 0.41811, 0.15092 and $\left.0.43273,(0.41811 \times 0.15092 \times 0.43273)^{1 / 3}=0.30113\right)$. A normalized mean CWV, $W_{\mathrm{AHP}}$ is then obtained.

Secondly (1.2.1.b), the performance vector for each alternative (i.e., $T_{A l t_{i}}, i=1 \ldots 4$ ) is determined by aggregating the subtotal scores for each construct from Table 1. For example, for $A l t_{1}$, the scores for the three sub-criteria for the main facility concern construct $\left(C_{3}\right)$ are 0.5 for ventilation/light (factor 7 in Table 1), 0.49367 for in-room facilities (factor 8 in Table 1) and 0.49791 for leisure/entertainment (factor 9 in Table 1) and these are summed as 1.49158 .

Thirdly (1.2.1.c), the subtotal score matrix, $T$, as shown in Table 5(a), is constructed by combining the four performance vectors. For example, the subtotal score for $A l t_{1}$ for the facility concern construct is shown in the $\left(A l t_{1}, C_{3}\right)$ cell of Table $5(\mathrm{a})$. Using the data from $T$ and Eq. (10), the normalized performance matrix, $\bar{T}$, which comprises the NPS vectors for the alternatives, is shown in Table 5(b). 
Table 5. The subtotal score matrix and the by-criterion normalized scores matrix

a) Subtotal score matrix $T$

\begin{tabular}{|c|c|c|c|c|c|}
\hline$T$ & $C_{1}$ & $C_{2}$ & $C_{3}$ & $C_{4}$ & $C_{5}$ \\
\hline$A l t_{1}$ & 1.10816 & 2.16464 & 1.49158 & 1.60812 & 0.97136 \\
\hline llt $_{2}$ & 0.45551 & 1.96575 & 1.57264 & 1.60812 & 1.01560 \\
\hline $\mathrm{Alt}_{3}$ & 1.24859 & 1.87613 & 1.50585 & 1.44690 & 1.12043 \\
\hline $\mathrm{Alt}_{4}$ & 0.63318 & 1.90121 & 1.39642 & 1.23793 & 0.82228 \\
\hline
\end{tabular}

b) Normalized subtotal score matrix $\bar{T}$

\begin{tabular}{|c|c|c|c|c|c|}
\hline $\bar{T}$ & $C_{1}$ & $C_{2}$ & $C_{3}$ & $C_{4}$ & $C_{5}$ \\
\hline$A l t_{1}$ & 0.55408 & 0.54116 & 0.49719 & 0.53604 & 0.48568 \\
\hline$A l t_{2}$ & 0.22775 & 0.49144 & 0.52421 & 0.53604 & 0.50780 \\
\hline$A l t_{3}$ & 0.62429 & 0.46903 & 0.50195 & 0.48230 & 0.56021 \\
\hline$A l t_{4}$ & 0.31659 & 0.47530 & 0.46547 & 0.41264 & 0.41114 \\
\hline
\end{tabular}

Fourthly (1.2.1.d), the SAW-ed scores (for the alternatives) are obtained using Eq. (12), as:

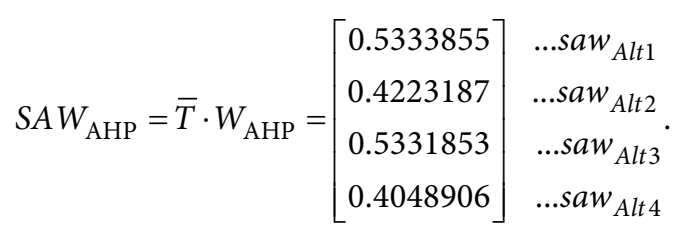

Finally, the ordinal rank, $R O_{\mathrm{AHP}}$, which is the preferential order for the alternatives based on the group opinion, is justified and prioritized as:

$$
R O_{\mathrm{AHP}}:\left(A l t_{1}\right) \succ\left(A l t_{3}\right) \succ\left(A l t_{2}\right) \succ\left(A l t_{4}\right) .
$$

\subsection{Solving using the IF-MADM in terms of the Ye-IFN model}

The solution process follows 1.2.2. Firstly (1.2.2.a), the score matrices, $S^{\mathrm{A}}, S^{\mathrm{B}}$ and $S^{\mathrm{C}}$, are derived using $D^{\mathrm{A}}, D^{\mathrm{B}}$ and $D^{\mathrm{C}}$. These are shown in Table 6.

Table 6. DMs' score matrices: by-criterion scores for the alternatives

a) Score matrix for $\mathrm{DM}^{\mathrm{A}}: S^{\mathrm{A}}$

\begin{tabular}{|c|c|c|c|c|c|}
\hline \multirow{2}{*}{$S^{\mathrm{A}}$ of $\mathrm{DM}^{\mathrm{A}}$} & \multicolumn{5}{|c|}{$S_{i j}^{\mathrm{A}}=\left(D_{i j}^{\mathrm{A}}(\mu())-D_{i j}^{\mathrm{A}}(v())\right)$} \\
\cline { 2 - 6 } & $C_{1}$ & $C_{2}$ & $C_{3}$ & $C_{4}$ & $C_{5}$ \\
\hline$A l t_{1}$ & -0.55 & 0.66 & 0.55 & 0.35 & 0.7 \\
\hline$A l t_{2}$ & -0.5 & 0.4 & 0.3 & 0.5 & 0.6 \\
\hline Alt $_{3}$ & -0.7 & 0.5 & 0.7 & 0.5 & 0.4 \\
\hline Alt $_{4}$ & -0.5 & 0.1 & 0.5 & 0.3 & 0.3 \\
\hline
\end{tabular}


b) Score matrix for $\mathrm{DM}^{\mathrm{B}}: S^{\mathrm{B}}$

\begin{tabular}{|c|c|c|c|c|c|}
\hline \multirow{2}{*}{$S^{\mathrm{B}}$ of $\mathrm{DM}^{\mathrm{B}}$} & \multicolumn{5}{|c|}{$S_{i j}^{\mathrm{B}}=\left(D_{i j}^{\mathrm{B}}(\mu())-D_{i j}^{\mathrm{B}}(v())\right)$} \\
\cline { 2 - 6 } & $C_{1}$ & $C_{2}$ & $C_{3}$ & $C_{4}$ & $C_{5}$ \\
\hline$A l t_{1}$ & -0.1 & -0.2 & 0.1 & 0.3 & 0.4 \\
\hline$A l t_{2}$ & -0.5 & -0.1 & 0.4 & 0.6 & 0.4 \\
\hline$A l t_{3}$ & -0.5 & 0.1 & 0.4 & 0.6 & 0.4 \\
\hline$A l t_{4}$ & -0.2 & 0.2 & 0.2 & -0.4 & 0.1 \\
\hline
\end{tabular}

c) Score matrix for $\mathrm{DM}^{\mathrm{C}}: S^{\mathrm{C}}$

\begin{tabular}{|c|c|c|c|c|c|}
\hline \multirow{2}{*}{$S^{\mathrm{C}}$ of $\mathrm{DM}^{\mathrm{C}}$} & \multicolumn{5}{|c|}{$S_{i j}^{\mathrm{C}}=\left(D_{i j}^{\mathrm{C}}(\mu())-D_{i j}^{\mathrm{C}}(v())\right)$} \\
\cline { 2 - 6 } & $C_{1}$ & $C_{2}$ & $C_{3}$ & $C_{4}$ & $C_{5}$ \\
\hline$A l t_{1}$ & -0.2 & 0.3 & 0.5 & 0.4 & 0.5 \\
\hline$A l t_{2}$ & -0.3 & 0.1 & 0.3 & 0.7 & 0.5 \\
\hline$A l t_{3}$ & 0.3 & 0.3 & 0.2 & -0.1 & 0.4 \\
\hline$A l t_{4}$ & -0.5 & 0.1 & 0.3 & -0.2 & 0.3 \\
\hline
\end{tabular}

The average score matrix, $S^{*}$, which is the distribution centre of the diversified opinions of the DMs, is then obtained using Eq. (13) as:

$$
S^{*}=\left[\begin{array}{ccccc}
-0.28 \overline{3} & 0.25 \overline{3} & 0.38 \overline{3} & 0.35 & 0.53 \overline{3} \\
-0.43 \overline{3} & 0.13 \overline{3} & 0.33 \overline{3} & 0.6 & 0.5 \\
-0.3 & 0.3 & 0.43 \overline{3} & 0.33 \overline{3} & 0.4 \\
-0.4 & 0.13 \overline{3} & 0.33 \overline{3} & -0.1 & 0.23 \overline{3}
\end{array}\right] .
$$

The Co-Co-Cos, $e^{\mathrm{A}}, e^{\mathrm{B}}$ and $e^{\mathrm{C}}$, each of which measures the distance between $S^{k}$ and $S^{*}$, are calculated. The results are listed in Table 7 (see Eq. (14)).

Table 7. The collective correlation coefficients (Co-Co-Cos) for the DMs

a) Collective correlation coefficient for $\mathrm{DM}^{\mathrm{A}}: e^{\mathrm{A}}$

\begin{tabular}{|c|c|c|c|c|}
\hline$e^{\mathrm{A}}$ & $i$ (Alternative Index) & Dividend & Divisor & Divided \\
\hline & 1 & 1.074446 & 1.0297 & 0.958355 \\
\hline & 2 & 1.014199 & 0.97 & 0.95642 \\
\hline & 3 & 1.02361 & 0.99 & 0.967165 \\
\hline & 4 & 0.493761 & 0.42 & 0.850614 \\
\hline$e^{\mathrm{A}}=$ & $\Sigma$ & & & 3.732553 \\
\hline
\end{tabular}


b) Collective correlation coefficient for $\mathrm{DM}^{\mathrm{B}}: e^{\mathrm{B}}$

\begin{tabular}{|c|c|c|c|c|}
\hline$e^{\mathrm{B}}$ & $i$ (Alternative Index) & Dividend & Divisor & Divided \\
\hline & 1 & 0.465281 & 0.334333 & 0.718562 \\
\hline & 2 & 0.93331 & 0.896667 & 0.960739 \\
\hline & 3 & 0.774955 & 0.713333 & 0.920483 \\
\hline & 4 & 0.320104 & 0.236667 & 0.739343 \\
\hline$e^{\mathrm{B}}=$ & $\Sigma$ & & & 3.339126 \\
\hline
\end{tabular}

c) Collective correlation coefficient for $\mathrm{DM}^{\mathrm{C}}: e^{\mathrm{C}}$

\begin{tabular}{|c|c|c|c|c|}
\hline$e^{\mathrm{C}}$ & $i$ (Alternative Index) & Dividend & Divisor & Divided \\
\hline & 1 & 0.74276 & 0.731 & 0.984167 \\
\hline & 2 & 0.928332 & 0.913333 & 0.983844 \\
\hline & 3 & 0.499166 & 0.213333 & 0.42738 \\
\hline & 4 & 0.411825 & 0.403333 & 0.97938 \\
\hline$e^{\mathrm{C}}=$ & $\Sigma$ & & & 3.374771 \\
\hline
\end{tabular}

Secondly (1.2.2.b), the normalized OWV, $\lambda_{\text {IFN }}$, is obtained using Eqs. (15) and (16), using the normalized opinion weights $e^{\mathrm{A}}, e^{\mathrm{B}}$ and $e^{\mathrm{C}}$. This is calculated as:

$$
\lambda_{\text {IFN }}=\left[\begin{array}{l}
\lambda^{\mathrm{A}} \\
\lambda^{\mathrm{B}} \\
\lambda^{\mathrm{C}}
\end{array}\right]=\operatorname{Norm}(E)=\operatorname{Norm}\left(\left[\begin{array}{l}
e^{\mathrm{A}} \\
e^{\mathrm{B}} \\
e^{\mathrm{C}}
\end{array}\right]\right)=\operatorname{Norm}\left(\left[\begin{array}{l}
3.732553 \\
3.339126 \\
3.374771
\end{array}\right]\right)=\left[\begin{array}{l}
0.357304 \\
0.319642 \\
0.323054
\end{array}\right] \ldots \lambda^{\mathrm{C}} .
$$

Given this normalized OWV, Eq. (17) gives a collective score matrix, $S$, by respectively multiplying the scalars $\lambda^{\mathrm{A}}, \lambda^{\mathrm{B}}$ and $\lambda^{\mathrm{C}}$, by $S^{\mathrm{A}}, S^{\mathrm{B}}$ and $S^{\mathrm{C}}$ and then aggregating these, as:

$$
\begin{aligned}
& S=\sum_{k \in\{A, B, C\}} \lambda^{k} S^{k}=\lambda^{\mathrm{A}} \cdot S^{\mathrm{A}}+\lambda^{\mathrm{B}} \cdot S^{\mathrm{B}}+\lambda^{\mathrm{C}} \cdot S^{\mathrm{C}}= \\
& \begin{array}{llllll}
C_{1} & C_{2} & C_{3} & C_{4} & C_{5}
\end{array} \\
& \begin{array}{l}
\text { Alt }_{1} \\
\text { Alt }_{2} \\
\text { Alt }_{3} \\
\text { Alt }_{4}
\end{array}\left[\begin{array}{lllll}
-0.293092 & 0.268808 & 0.390008 & 0.350171 & 0.539496 \\
-0.435389 & 0.143263 & 0.331964 & 0.596575 & 0.503766 \\
-0.404107 & 0.131964 & 0.339496 & -0.08528 & 0.236072
\end{array}\right] \text {. }
\end{aligned}
$$

Thirdly (1.2.2.c), in order to solve for an optimal CWV $\left(W_{I F N}^{*}\right)$ that is based on the group opinion, the LP model in Appendix D is constructed using Eq. (18). The model takes the elemental values in $S$ as the objective function parameters. It is then solved using LINGO (Schrage, 2002) and the optimal solution for CWV is obtained, as:

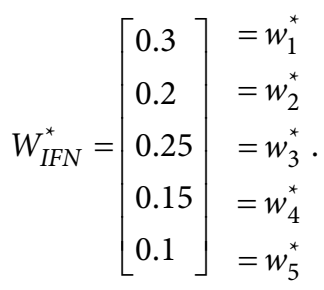


Fourthly (1.2.2.d), by multiplying $S$ by $W_{\text {IFN }}^{\star}$ using Eq. (19), the score vector, $S A W_{\text {IFN }}$, is:

$$
S A W_{\mathrm{IFN}}=S \cdot W_{\mathrm{IFN}}^{*}=\left[\begin{array}{c}
0.169811 \\
0.120890 \\
0.168966 \\
0.000850
\end{array}\right] \ldots s a w_{\text {Alt } 1} \ldots w_{\text {Alt } 2} .
$$

Finally, the ordinal rank that is given by $S A W_{\mathrm{IFN}}, R O_{\mathrm{IFN}}$, which is the decision group's preferential order for the alternatives, is:

$$
R O_{\text {IFN }}:\left(A l t_{1}\right) \succ\left(A l t_{3}\right) \succ\left(A l t_{2}\right) \succ\left(A l t_{4}\right) .
$$

\section{Comparisons and implications}

In terms of the four effectiveness measures for IF-MADM modelling, Section 2 empirically demonstrates the applicability of IF-MADM modelling for a group decision. In this section, the efficacy of the model is considered. The final rank orders (ROs), CWVs and OWVs that are obtained in Section 2 using both models are respectively subjected to 'pair-wise comparisons' in subsections 3.1,3.2, and 3.3. These processes involve the proposed similarity confirmation method (1.3.1), which uses a cardinal base (using the assessed scores, rather than the ordinal ranks) to verify the results (i.e., the similarities in the ranks). Because the efficacy of IF-MADM can be 'measured' in this way (i.e., by reference to the results that are obtained using another trustworthy model; see 1.3), in order to verify that using IF-MADM is as efficacious as using other MADM models (except for the AHP), for the same decision case, an additional robustness test is also performed using TOPSIS and further comparisons are made in 3.4. In subsection 3.5, the observations that pertain to the efficiency and informativeness of the process are summarized.

\subsection{Comparing the Ordinal Ranks (ROs)}

The results that are obtained in Section 2 show that the two final rank orders are identical: $\left(A l t_{1}\right) \succ\left(A l t_{3}\right) \succ\left(A l t_{2}\right) \succ\left(A l t_{4}\right)$. This first observation demonstrates that both approaches the IF-MADM and AHP - yield the same rank order. Figure 2 shows a simple graphical view of the two score vectors (i.e., $S A W_{\text {AHP }}$ and $S A W_{\text {IFN }}$ in Eq. (20) and Eq. (26), respectively). Even though $S A W_{\text {IFN }}$ looks different to $S A W_{\mathrm{AHP}}$ because of the scales, it is intuitive that the alternative set $\left\{A l t_{1}, A l t_{3}\right\}$ dominates $\left\{A l t_{2}\right\}$ and then $\left\{A l t_{4}\right\}$. In other words, $\left\{A l t_{1}, A l t_{3}\right\}$ constitutes a kernel set, as defined by ELECTRE (Roy, 1991).

However, except for this similarity (i.e., identical rank orders), whether the SAW-ed score vectors are really indifferent (or not) should be made evident for this observation. The similarity confirmation method that is proposed in 1.3.1 is employed.

Initially, it is determined whether the SAW-ed score vectors are identical populations. Standardizing the score vectors (by: $(s a w-\mu) / \sigma$, step 2 of 1.3.1) and using the Wilcoxon rank-sum test in $\mathrm{R}$, it is seen that: "W $=6, p$-value $=0.6857$."

Note that if the paired signed rank test is used: "V $=4, p$-value $=0.875$." 


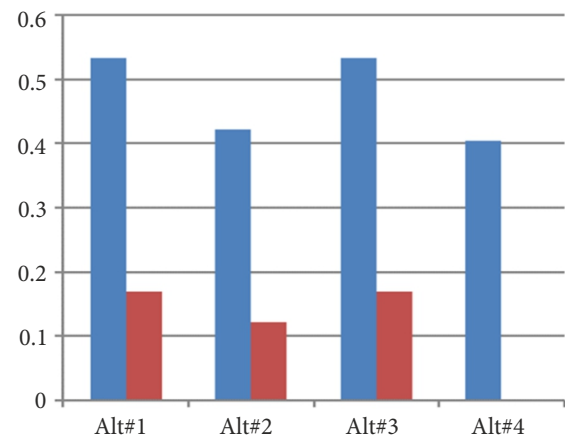

Final scores by AHP

Final scores by Ye-IFN

Figure 2. A comparison of the magnitudes of the final score vectors

These results show that there is very little evidence that these two score vectors ( $S A W_{\mathrm{AHP}}$ and $S A W_{\text {IFN }}$ ) are from non-identical populations, because the $p$ value is (as high as) 0.875 . This partially confirms that they are identical populations (step 3 of 1.3.1).

It is also necessary to determine whether these two vectors are drawn from (or form) the same distribution. A two-sample Kolmogorov-Smirnov test on the two standardised vectors (without reordering) shows that: " $\mathrm{D}=0.5, p$-value $=0.7714$."

This shows that there is little chance that they are from different (non-identical) distributions, because the $p$ value is 0.7714 . In other words, it is reasonable to assume that they come from the same distribution (step 4 of 1.3.1). Therefore, the similarity in rank orders (an identical preferential order for the alternatives) is confirmed.

\subsection{Comparing the Criteria Weight Vectors (CWVs)}

The elements in $W_{\text {AHP }}$ represents an order of priority for the constructs (in Table $4(\mathrm{~d})$ ). The values for the calculated normalized mean CWV, $W_{\mathrm{AHP}}$ shows that the weights of the constructs are in the order: $w_{1}>w_{2}>w_{4}>w_{3}>w_{5}$, which is $\mathrm{CO}_{\mathrm{AHP}}:\left(C_{1}\right) \succ\left(C_{2}\right) \succ\left(C_{4}\right) \succ\left(C_{3}\right) \succ\left(C_{5}\right)$. Using Eq. (25), the values for $W_{\text {IFN }}$ indicate another order: $w_{1}>w_{3}>w_{2}>w_{4}>w_{5}$, which is $\mathrm{CO}_{\mathrm{IFN}}:\left(C_{1}\right) \succ\left(C_{3}\right) \succ\left(C_{2}\right) \succ\left(C_{4}\right) \succ\left(C_{5}\right)$.

These two CWVs seem to be different, but $W_{\mathrm{AHP}}$ and $W_{\mathrm{IFN}}$ are quite consistent, because for each $j(j=1, . ., 5),\left|w_{\mathrm{AHP}_{j}}-w_{\mathrm{IFN}_{j}}\right| \leq 0.075$ and the one-dimensional Euclidean distance between them is only $\Delta W=\left|W_{\mathrm{AHP}}-W_{\mathrm{IFN}}\right|=\left[\begin{array}{lllll}0.024 & 0.027 & 0.075 & 0.067 & 0.043\end{array}\right]^{\prime}$. This is shown in Figure 3. In the figure, a positive deviation from $w_{\mathrm{AHP}_{j}}$ to $w_{\mathrm{IFN}_{j}}$ is marked in white and a negative deviation is marked black. The magnitudes for $\Delta W$ are also shown. $\mathrm{A}$ similarity is observed (step 1 in 1.3.1).

Evidence of this similarity can be also found using the similarity confirmation method by checking whether there are dissimilar elements in the CWVs, with respect to the weight values, $w_{1} \ldots w_{5}$. Again the paired signed rank test is used. Because CWVs must have the same scale, these two vectors need not be standardised (i.e., step 2 of the method that is shown in 1.3.1 is omitted). 


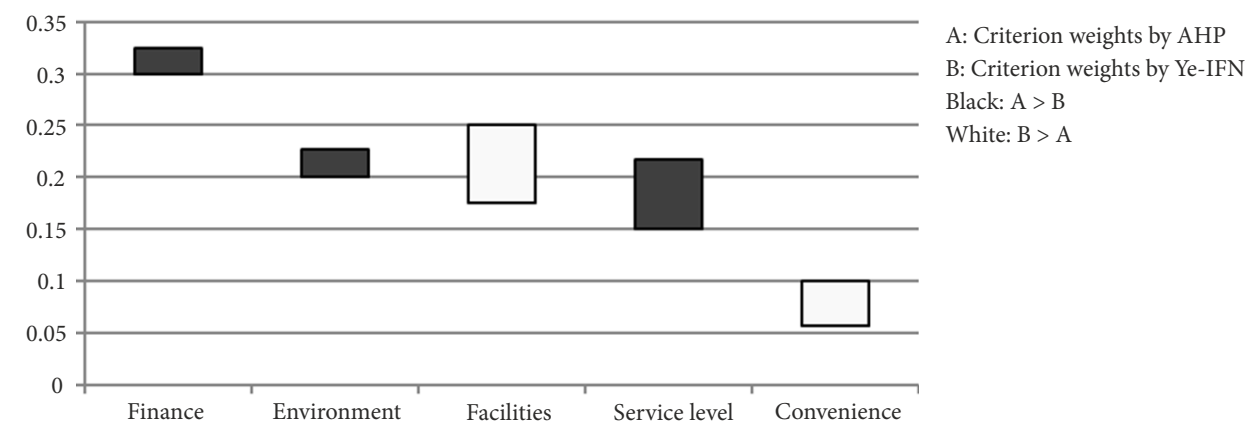

Figure 3. Differences (directional) between the assessed criterion weights for the two CWVs

Using the paired signed rank test (step 3 of the method) it is seen that: "V $=8, p$-value $=1$."

A two-sample Kolmogorov-Smirnov test (step 4 of the method) yields: " $D=0.2, p$-value $=1$.

These results show that the two CWV's are neither non-identical populations nor from different distributions. The extreme values for $p$ of 1.0 give strong confidence that they are not different.

\subsection{Comparing the Opinion Weights Vectors (OWVs) for DMs}

As discussed in 1.3, the standard AHP approach applies equal opinion weights, although it does not produce any opinion weight as its sub-product (see also Appendix E). Therefore, if AHP is used, the value of OWV is:

$$
\lambda_{\mathrm{AHP}}=\left[\begin{array}{c}
1 / 3 \\
1 / 3 \\
1 / 3
\end{array}\right]=\left[\begin{array}{l}
0.334 \\
0.333 \\
0.333
\end{array}\right] \begin{aligned}
& \ldots \lambda_{\mathrm{AHP}}^{\mathrm{A}} \\
& \ldots \lambda_{\mathrm{AHP}}^{\mathrm{B}} \\
& \ldots \lambda_{\mathrm{AHP}}^{\mathrm{C}}
\end{aligned} .
$$

Based on this, the absolute difference between $\lambda_{\mathrm{AHP}}$ and $\lambda_{\text {IFN }}$ (i.e., the RHS's of Eq. (28) and Eq. (23)) is calculated as:

$$
\Delta \lambda=\left|\lambda_{\mathrm{AHP}}-\lambda_{\mathrm{IFN}}\right|=\left[\begin{array}{l}
0.0233 \\
0.0134 \\
0.0099
\end{array}\right] .
$$

At first, the RHS of Eq. (29) shows that using the IF-MADM model, the opinion weights for the DMs approximate the weights that are assumed by AHP. Figure 4 shows this fact visually.

The fact that the two OWVs are quite close to each other (i.e., $\lambda_{\mathrm{IFN}}^{k} \leftrightarrow \lambda_{\mathrm{AHP}}^{k}, \forall k \in\{\mathrm{A}, \mathrm{B}, \mathrm{C}\}$ ) supports the previous results, because the comparisons are made assuming similar opinion weights.

In addition, in Figure 4, the elements of the $\lambda_{\text {IFN }}$ vector are almost equal. This implies that the individual 'net preference' opinions of the DMs that are expressed in the IFNs (i.e., in $S^{k}, k \in\{\mathrm{A}, \mathrm{B}, \mathrm{C}\}$ ) are close to the distribution centre (i.e., $S^{*}$ ). This means that the DM's opinions have no outliers; i.e., no weight for any DM in this decision group is an extreme. 


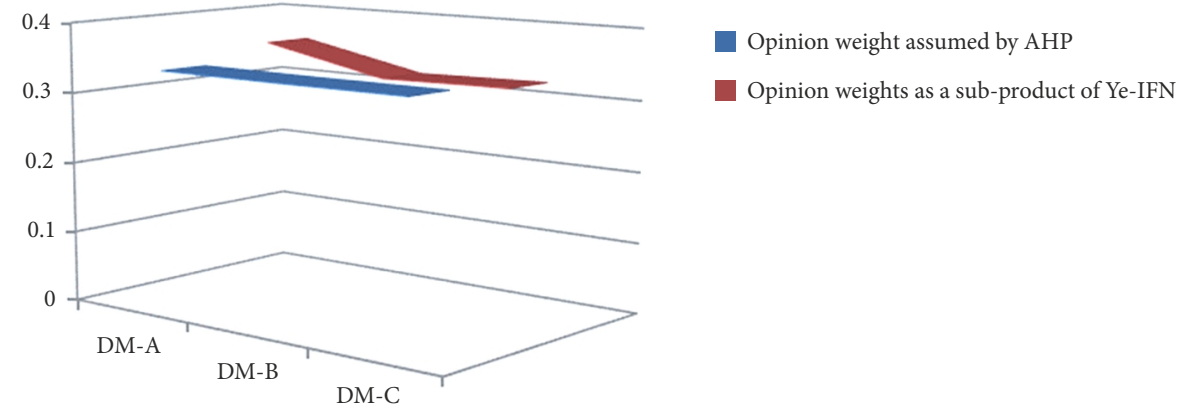

Figure 4. Comparing the OWVs

This is unsurprising because the DM's were classmates, so their opinions are quite homogeneous (see Appendix A).

Finally, as an IF-MADM model, the used Ye-IFN can actuarially and automatically assess the individual opinion weights of the DMs, but the AHP cannot. It can produce precise but slightly different opinion weights $\left(\lambda_{\mathrm{IFN}}^{k}\right)$ as its sub-products, despite the fact that they are approximated to an equal weight for the case decision.

\subsection{Results using TOPSIS and further comparisons for the robustness test}

The previous subsections verify the efficacy of IF-MADM in comparison with AHP, in terms of the observed and verified similarity in the final ordinal ranks (ROs) and CWVs, subject to the condition that the OWVs are almost equal. TOPSIS is then used to further confirm these positive outcomes.

For this supplementary robustness test, because of the similarities that are evident from previous elements of this study, it is reasonable to assume that $W_{\text {TOPSIS }}=W_{\text {AHP }}$ and $\lambda_{\text {TOPSIS }}=\lambda_{\mathrm{AHP}}$, as the manifests for CWV and OWV during TOPSIS modelling. Therefore, this process mirrors the AHP+TOPSIS approach. The literature also shows many applications of this hybrid model (see the literature survey for AHP and TOPSIS: the trustworthy alternative approaches in the Introduction section).

By executing the self-written scripts that implement the relevant algorithms for TOPSIS in $\mathrm{R}$ language and using the data set, the final result is:

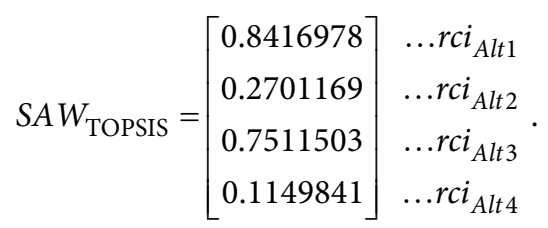

The calculation of this equation follows standard TOPSIS rules. $r c i_{\text {Alti }}$ is the relative closeness index (RCI) for alternative $i$ and is computed as:

$$
r c i_{A l t i}=d\left(A l t_{i}, I^{-}\right) /\left(d\left(A l t_{i}, I^{-}\right)+d\left(A l t_{i}, I^{+}\right)\right),
$$

where $d(\mathrm{~A}, \mathrm{~B})$ is the function that measures the distance between two performance vectors, 
A and $\mathrm{B}$, in the attribute (objective) space and $\mathrm{I}^{+}$and $\mathrm{I}^{-}$are, respectively, the positive and negative (anti-) ideal solutions for the decision system. These are determined using the best and worst performance for the alternatives for each criterion. Because the RCI is also a type of SAW-ed score, this vector is named SAW, for consistency.

The elemental values for the $S A W_{\text {TOPSIS }}$ vector give a rank order, $R O_{\text {TOPSIS: }}$ $\left(A l t_{1}\right) \succ\left(A l t_{3}\right) \succ\left(A l t_{2}\right) \succ\left(A l t_{4}\right)$, which is different to $R O_{\mathrm{AHP}}$ and $R O_{\mathrm{IFN}}$, both of which yield the order: $\left(A l t_{3}\right) \succ\left(A l t_{1}\right) \succ\left(A l t_{2}\right) \succ\left(A l t_{4}\right)$. However, as $R O_{\text {TOPSIS }}$ does not contradict the inference that is made in 3.1 that $\left\{A l t_{1}, A l t_{3}\right\}$ constitutes a kernel set, the similarity between $S A W_{\text {TOPSIS }}$ and the $S A W_{\mathrm{AHP}}$ and $S A W_{\mathrm{IFN}}$ is of interest.

Using the similarity confirmation method again and standardizing $S A W_{\text {TOPSIS }}$, the nonparametric test functions are called in $\mathrm{R}$ to perform the relevant tests, using the ( $S A W_{\text {TOPSIS, }}$ $\left.S A W_{\mathrm{AHP}}\right)$ and ( $\left.S A W_{\mathrm{TOPSIS}}, S A W_{\mathrm{IFN}}\right)$ vector pairs as the input. The paired signed rank tests yield the following outcome:

For the ( $\left.S A W_{\text {TOPSIS }}, S A W_{\mathrm{AHP}}\right)$ pair: "V $=5, p$-value $=1$."

For the ( $\left.S A W_{\text {TOPSIS }}, S A W_{\text {IFN }}\right)$ pair: "V $=6$, $p$-value $=0.875$."

Additional two-sample Kolmogorov-Smirnov tests show:

For the $\left(S A W_{\text {TOPSIS }}, S A W_{\mathrm{AHP}}\right)$ pair: "D $=0.25, p$-value $=1$."

For the $\left(S A W_{\text {TOPSIS }}, S A W_{\text {IFN }}\right)$ pair: "D $=0.5, p$-value $=0.7714$."

All of the $p$ values are quite high. This implies that in comparison to either $S A W_{\mathrm{AHP}}$ or $S A W_{\text {IFN }}, S A W_{\text {TOPSIS }}$ forms neither a non-identical population, nor is it from a different distribution. Table 8 summarizes these results.

These $p$ values also show that the ( $\left.S A W_{\text {TOPSIS }}, S A W_{\mathrm{AHP}}\right)$ pair of vectors are more likely to be identical populations that are from the same distribution than the $\left(S A W_{\text {TOPSIS }}, S A W_{\text {IFN }}\right)$ pair. This is reasonable because $S A W_{\mathrm{AHP}}$ is obtained using the AHP+SAW method and the $S A W_{\text {TOPSIS }}$ is obtained using the AHP+TOPSIS method. Both of these involve the use of AHP to determine the CWV and they assume an equal OWV whose elements are equal so this outcome is not surprising, despite the fact that the logic for SAW and TOPSIS is totally different.

Table 8. Summary of the test results for the accessed scores, using different methods

\begin{tabular}{|c|c|c|c|c|}
\hline $\begin{array}{l}\text { P for Signed Rank } \\
\text { Test }\end{array}$ & \multirow[b]{2}{*}{$S A W_{\mathrm{AHP}}$} & \multirow[b]{2}{*}{$S A W_{\text {IFN }}$} & \multirow[b]{2}{*}{$S A W_{\text {TOPSIS }}$} & \multirow[b]{2}{*}{ Implications for population and distribution } \\
\hline $\begin{array}{l}\text { p for Two-sample } \\
\text { K.-S. Test }\end{array}$ & & & & \\
\hline \multirow{2}{*}{$S A W_{\mathrm{AHP}}$} & - & & & \\
\hline & - & & & \\
\hline \multirow[b]{2}{*}{$S A W_{\mathrm{IFN}}$} & 0.875 & - & & \multirow{2}{*}{$\begin{array}{l}S A W_{\mathrm{AHP}} \text { and } S A W_{\mathrm{IFN}} \text { are likely to be } \\
\text { identical populations and from the same } \\
\text { distribution }\end{array}$} \\
\hline & 0.7714 & - & & \\
\hline \multirow{2}{*}{$S A W_{\text {TOPSIS }}$} & 1 & 0.875 & - & \multirow{2}{*}{$\begin{array}{l}S A W_{\text {TOPSIS }} \text { and } S A W_{\text {IFN }} \text { are likely to be } \\
\text { identical populations and from the same } \\
\text { distribution, and } S A W_{\text {TOPSIS }} \text { and } S A W_{\mathrm{AHP}} \\
\text { are very likely to be }\end{array}$} \\
\hline & 1 & 0.7714 & - & \\
\hline
\end{tabular}


However, the similarities between $S A W_{\text {TOPSIS }}$ and $S A W_{\mathrm{AHP}}$ are not as important as those between $S A W_{\text {TOPSIS }}$ and $S A W_{\text {IFN }}$. Although the $p$ values after testing the ( $S A W_{\text {TOPSIS }}, S A W$ IFN $)$ pair are not as perfect as those for ( $\left.S A W_{\text {TOPSIS }}, S A W_{\mathrm{AHP}}\right)$ (where both $p$ values are 1 ), they are high enough. These sufficiently high $p$ values further evidence the effectiveness of IF-MADM modelling, in that the efficacy of this approach is cross-validated using more than one widely used model. This is the main purpose of the robustness test.

\subsection{Implications and discussions}

In this subsection, the main findings, in terms of the applicability and the efficacy measures, are summarized from the previous subsections. The findings for the efficiency and informativeness measures are discussed in terms of the observations that are made:

- The applicability of IF-MADM. This study uses an IF-MADM model to solve a real group decision problem. The data is sourced from both interviews and the existing data set. In this sense, this study details an empirical application of IF-MADM and a modelling case. Since relatively few real case studies in the healthcare field use IFMADM, this study extends the application of IF-MADM. In terms of problem solving, this study supplements the field of non-clinical healthcare decision-making.

- The efficacy of IF-MADM. In this study, the same group-MADM decision case is solved using different MADM methods. Similarities in the results are identified and further confirmed using the proposed similarity confirmation method (see 3.1-3.4). These are important elements in determining the efficacy of IF-MADM modelling, since the main alternative approach (AHP) and the approach that is used for the robustness test (TOPSIS) are both trustworthy (common and popular according to the studied literature) approaches and they have similar MADM properties for fair and meaningful comparisons (i.e., from a methodological viewpoint, they are all ratio-scaled, compensatory group MADM models). Although it is seen that there are similarities between the ordinal ranks, the results for the (TOPSIS, IF-MADM) pair are slightly dissimilar but the results for the (TOPSIS, AHP) pair are very similar. This is reasonable because the application process for IF-MADM is totally heterogeneous; i.e., it is distinguished from other methods by its alternative assessment logic and the investigation/analysis of human data from the beginning. For the studied group decision, the three models give the same or very similar results. Given the fair comparison basis, the efficacy of the IF-MADM approach is therefore supported. This is an important indicator that, in practice, IF-MADM is an acceptable approach for making real group decisions, even though it has fewer current applications.

- The efficiency of IF-MADM. In terms of the third effectiveness factor, the solution process is benchmarked using the observational measures: data survey time and model solution time. The relevant durations that were measured during the experiment are presented in Table 9. 
Table 9. The efficiency benchmark using different methods

\begin{tabular}{|c|c|c|c|c|}
\hline Measured time using (mm:ss) & AHP + SAW & IF-MADM & AHP + TOPSIS & Remarks \\
\hline $\begin{array}{l}\text { Data Survey: Expert } \\
\text { Questionnaire: DM-A } \\
\text { (Observed Time on } \\
\text { Communications) }\end{array}$ & $\begin{array}{l}06: 30 \\
(03: 59)\end{array}$ & - & $\begin{array}{c}06: 30 \\
(03: 59)\end{array}$ & $2: 31$ on filling \\
\hline $\begin{array}{l}\text { Data Survey: Expert } \\
\text { Questionnaire: DM-B } \\
\text { (Observed Time on } \\
\text { Communications) }\end{array}$ & $\begin{array}{c}06: 28 \\
(03: 38)\end{array}$ & - & $\begin{array}{c}06: 28 \\
(03: 38)\end{array}$ & 2:50 on filling \\
\hline $\begin{array}{l}\text { 2nd Round Expert } \\
\text { Questionnaire: DM-B } \\
\text { (Observed Time on } \\
\text { Communications) }\end{array}$ & $\begin{array}{c}05: 56 \\
(02: 12)\end{array}$ & - & $\begin{array}{c}05: 56 \\
(02: 12)\end{array}$ & $\begin{array}{l}\text { 3:44 on filling } \\
\text { Subtotal for DM-B: } \\
\text { 12:24 (05:50) }\end{array}$ \\
\hline $\begin{array}{l}\text { Data Survey: Expert } \\
\text { Questionnaire: DM-C } \\
\text { (Observed Time on } \\
\text { Communications) }\end{array}$ & $\begin{array}{c}05: 14 \\
(03: 16)\end{array}$ & - & $\begin{array}{c}05: 14 \\
(03: 16)\end{array}$ & 1:58 on filling \\
\hline $\begin{array}{l}\text { Data Survey: IFN } \\
\text { Questionnaire: DM-A } \\
\text { (Observed Time on } \\
\text { Communications) }\end{array}$ & - & $\begin{array}{c}07: 10 \\
(04: 24)\end{array}$ & - & 2:46 on filling \\
\hline $\begin{array}{l}\text { Data Survey: IFN } \\
\text { Questionnaire: DM-B } \\
\text { (Observed Time on } \\
\text { Communications) }\end{array}$ & - & $\begin{array}{c}07: 36 \\
(04: 29)\end{array}$ & - & 3:07 on filling \\
\hline $\begin{array}{l}\text { Data Survey: IFN } \\
\text { Questionnaire: DM-C } \\
\text { (Observed Time on } \\
\text { Communications) }\end{array}$ & - & $\begin{array}{c}06: 50 \\
(04: 14)\end{array}$ & - & $2: 36$ on filling \\
\hline $\begin{array}{l}\text { Model Computation Time } \\
\text { Running the R Scripts }\end{array}$ & 00:01.640 & 00:00.780 & 00:01.810 & $\begin{array}{l}\text { See the following } \\
\text { table notes }\end{array}$ \\
\hline LINGO & - & 00:00 & - & $\begin{array}{l}\text { See the following } \\
\text { table notes }\end{array}$ \\
\hline $\begin{array}{l}\text { Total time elapsed (mm:ss) } \\
\text { (rounded) }\end{array}$ & $24: 10$ & $21: 37$ & $24: 10$ & \\
\hline
\end{tabular}

Notes: 1) The embraced measured time for communications is the time taken for illustrations, explanations and inquiries during the interview; 2) For AHP+SAW/AHP+TOPSIS, the model computational time includes the time spent on all of the AHP calculations and the SAW/TOPSIS calculations, except for the consistency analysis; 3) For IF-MADM, the model computational time includes calculating all of the relevant steps, except the CWV-determination phase using LINGO; 4) The data input time (inputting data in a specific format, such as .csv) is omitted because it depends significantly on the researcher, but for the same researcher, it is fixed; 5) The time taken to load data in R for each model by running the read.csv() functions is not included; the time precision for the millisecond value is only given to two decimal places, because the proc.time() function is used, based on the default time precision setting in the Windows version of $\mathrm{R} ; 6$ ) The LINGO interface does not show the milliseconds but since the linear solver (with the global solver turned on) dialog shows mm:ss $=00: 00$, it is recorded as such. 
(1) Data survey time. Intuitively, an AHP survey takes longer because of the need for repeated interviews. In this study, a $\mathrm{DM}_{\mathrm{B}}$ was interviewed twice to pass the CR check. Table 9 shows that despite the fact that an IFN-based interview only requires one round, much extra time is required for communication, such as explaining IFN (see sections 1.1 and 2.1), because the DMs had no experience of this style of questionnaire. More critically, as with this survey, the questionnaire design can be prone to error (verbal terms are not self-explanatory or not easily understood), so further explanation is required. For example, when answering the questions, the DMs interpreted the question, "What probability is this alternative membership with the $C_{1}$ construct (finance)?" as "What probability is this alternative attribute to financial concerns (pressures) for you?". This is because in Chinese, finance (Cai- $\mathrm{Wu}$ ) sometimes infers to a financial problem, and not a financial benefit. The same confusion does not result for $C_{2}-C_{5}$ because in Chinese, these names have a default positive association. Based on these observations, each approach has its own inevitable survey time overhead, so it is difficult to determine which takes less time because this issue is context-dependent.

(2) Model solution time. As seen in 2.3, it is obvious that most computations for the Ye-IFN IF-MADM model are simply arithmetic calculations (i.e., additions, multiplications and divisions), but obtaining the optimal $\mathrm{CWV}$ further requires mathematical modelling (Eq. (25) with Eq. (18)). However, the evaluation of the Co-Co-Cos $\left(e^{\mathrm{A}}, e^{\mathrm{B}}\right.$ and $\left.e^{\mathrm{C}}\right)$ is relatively complex. At the survey stage, AHP involves computing the C.I. and the table lookups for C.R. However, this cannot be counted as a part of the model solution time because it is context dependent (one additional round of AHP survey results in one additional consistency analysis). For subsequent computations when the data is ready, there is then a considerable amount of matrix multiplication and geometrical powering, which are both time-costly for the computer. This is why the computational times in Table 9 for AHP+SAW and AHP+TOPSIS are both twice those for IF-MADM. However, if the computation processes for these two approaches are not strictly benchmarked algorithmically (in terms of asymptotic order), they involve almost the same degree of human involvement. Because computational resources are rarely limited nowadays (i.e., the computation time is at a second level in Table 9, rather than minute), human operations in a computational task create a bottleneck, especially for any group MADM problem of the size of that studied (i.e., $\left.P=\left(\left(D M_{k}, A l t_{i}, C_{j}\right) \mid k \in\{A, B, C\}, i=1 . .4, j=1 . .5\right)\right)$. Therefore, regardless of the method that is used, the actual time that is spent on the solution process is negligible in comparison to the time that is required for the data survey.

Using these two measures, there is neither strong evidence to show that one method outranks the other, in terms of data survey time, nor a solid basis for this argument in terms of the total time spent, even though the model solution time for the IF-MADM model is about half that for the other AHP-hybrid models, but the gap is too small to be of consequence. The only claim that can be made is that data survey time is the key efficiency factor. Therefore, regardless of the approach that is used, reducing the data survey time is a priority if efficiency is to be increased. In particular, if the IFN-based approach is to avoid the negative-thought problem that can result in a longer survey time, a questionnaire that contains linguistic variables that embed the IFNs is preferable to asking confusing membership and non-membership questions directly. 
- The informativeness of IF-MADM. As shown in 3.3, during the solution process, the Ye-IFN model assesses the weights of DMs' opinions using only limited inputs; the other two models do not. This is the additional information that is obtained by the IF-MADM model. AHP provides additional information for/from the consistency analysis, but the other two models do not. TOPSIS also offers additional information about the ideal and anti-ideal solutions for the given decision system, along with the solution process, but the other two do not. In this sense, there is no single preferred approach when informativeness is the sole measure. This implies that the suitability of a model is partly determined by the desired sub product that the model provides. This supports the statement that multi-criteria decision-making methods have different issues when used in different contexts (Erdogan et al., 2017).

Consequentially, the overall effectiveness of the IF-MADM approach is verified, in that it is shown to be able to solve the group decision problem in practice (applicable) and in that the solutions are identical or similar to those that are obtained using other trustworthy MADM models (efficacious), subject to the fact that it is as efficient as other models (i.e., the time for the major questionnaire filling task are on a par, see the last column in Table 9). The informativeness cannot be compared because there are different types of model sub-product and the different models have different strengths.

As such, the effectiveness of the IF-MADM approach has been benchmarked in terms of four dimensions. The measurement of these dimensions and how they are organized to verify the effectiveness are also methodological contributions of this study, even though things are not always really (quantitatively) measured. That is, the way in which the applicability is measured in terms of an empirical case, the way in which the efficacy is measured by reference to the solutions from other trustworthy models and using the proposed similarity confirmation method, the way in which the efficiency is measured in terms of both survey time and model solution time and the way in which the informativeness is measured by examining the model sub-products have formed a systematic flow that verifies the overall effectiveness of any (new) MADM model.

\section{Conclusions}

This study determines the effectiveness of the IF-MADM approach for making practical group decisions. It also supplements the field of MADM by comparing the IF-MADM approach with non-IFN-based MADM, since despite intensive development worldwide, few attempts have been made to systematically present the theoretical basis and developments in MCDM (MADM) methods (Zavadskas, 2014).

The systematic flow that compares and benchmarks two or more MADM models is a methodological contribution. This method comprehensively measures and verifies the effectiveness of a MADM model in four dimensions: the applicability, as measured in terms of empirical case application; the efficacy, as measured by reference to the solutions from other trustworthy MADM models and using the proposed similarity confirmation method; the efficiency, as measured in terms of both survey time and model solution time, and the informativeness, as measured by examining the model sub-products to achieve a more informed 
decision. Except for the flow itself, the entire process involves critical concepts, such as the use of an appropriate empirical case, the selection of suitable alternative approaches (i.e., the main rival approach, AHP, and another approach for a robustness test, TOPSIS) and the use of statistical tests to confirm the observed similarity in the results that are obtained using different MADM models.

The proposed similarity confirmation method is another key methodological contribution of this study. Generally speaking, this method is related to the way in which the observable similarity between the final ordinal ranks is confirmed by verifying what is used to determine them; i.e., the (SAW-ed) score vectors using two MADM models. For this purpose, the two-sample non-parametric tests that are frequently used in the data analytics field are used. If it cannot be asserted that two score vectors are from non-identical populations and/or from non-identical distributions and there is little evidence to support this, the observed similarity in the final ordinal ranks can be confirmed by reference to these facts. As discussed in 1.3.1, this statistically based method is intrinsically different to a geometrically based method (e.g., the spherical distance method). The application contexts are also different, in that both the data inputs and the similarity (distance) measurement targets are heterogeneous.

For practitioners, the results of this study have significant managerial implications for choosing and applying MADM models. This study shows that DM's can successfully complete the IFN-based questionnaires. The experiments also show the effectiveness of IF-MADM for group decisions in practice, compared to other trustworthy approaches such as AHP and TOPSIS. In other words, the empirical evidence of this study supports the use of IF-MADM (in addition to other popular MADM methods), but there are also advantages to IFN-style surveys and for model applications in practice.

Possible future research could use the flow of this study to compare another set of current MADM approaches, some of which have extension models that use the first stage of AHP (pairwise comparisons to obtain the CWV(s)), e.g., AHP+GTMA (Singh \& Rao, 2011; Zhuang, Chiang, Su, \& Chen, 2017). Similar studies will be also necessary when a new MADM model is proposed and its practical effectiveness must be verified.

Another possible direction is a hybrid approach that uses the OWV that is assessed by the IF-MADM model as a basis for aggregating the opinions of DM's in AHP (i.e., using the information that is obtained from IF-MADM to supplement AHP). The standard AHP approach does not assess OWV, so the geometric mean for these opinions is calculated. In this case, the assessed OWV (e.g., by the Ye-IFN model based on the Co-Co-Cos) could be used when AHP is calculating the aggregated opinion (e.g., for the elements in the aggregated CWV), while all other processes remain unchanged. Except for this, a CWV that is assessed by the AHP is also an alternative to 1.2.2(c), which is the MODM-based CWV-determination phase of the model (this uses the information that is obtained from AHP to supplement IFMADM). As this has been shown to be practically effective for a web-based multi-participant DSS study (Zhuang et al., 2018), the theoretical basis for this hybrid is still a subject for study.

As discussed in 3.5, in order to resolve the ambiguity in IFN-style polling, which involves membership/non-membership questions, the questionnaire could be redesigned in such a way that linguistic variables are used to embed the IFNs. As for the AHP-style polling, more accurate methods could be considered for the initial CWV-determination phase. 
Finally, the theory of data-driven decision-making (DDDM, or $\left[\mathrm{D}^{3} \mathrm{M}\right]$ ) (Marr, 2016) supports the maxims that were established by Herbert Simon (Simon, 1976), who stated that decision-making is the heart of business administration and human-computer interaction (HCI) is required. In the age of big data, a successful decision process must involve 'human-data-interaction' (HDI), because even though data is key to driving decisions, based on its availability, human insights are still necessary (i.e., from the DMs) because "big data's power does not erase the need for vision or human insight" (McAfee, Brynjolfsson, Davenport, Patil, \& Barton, 2012).

In this study, all of the compared models can be viewed as $\mathrm{D}^{3} \mathrm{M}$ methods, in that the decision data that is shown in Table 1 is now ubiquitous, or at least easily available (data re-collection, analytic and mining works are only required for the absent part), but human data is still required (using the concepts of HDI). For example, in contrast to pure AHP, where pairwise comparisons must be made at the second stage in order to determine the relative priority for the alternatives (Janic \& Reggiani, 2002), common methods such as AHP+SAW and AHP+TOPSIS use AHP in the first stage and another MADM method to utilize the computer data log in the second. That is, the second stage of pure AHP, which also involves human interaction, can be (and has been) substituted with data, despite the longstanding popularity of pure AHP (Oh \& Park, 2014). However, human involvement in the first stage of AHP is still inevitable. In other words, during the mind-mining process for a decision, the DM is irreplaceable (by the data), but processes that do not involve mind mining can utilize data from data mining or BI; i.e., a true HDI. In this sense, the MADM models that are used in this study use data from both machines and humans, so they are $\mathrm{D}^{3} \mathrm{M}$ methods.

In terms of methodological development, $\mathrm{D}^{3} \mathrm{M}$ also reflects the fact that MADM methods are changing (Ramanathan, Mathirajan, \& Ravindran, 2017). The current series of AHP-hybrid (i.e., AHP+XXX) models demonstrates this fact. Therefore, in terms of MADM, $\mathrm{D}^{3} \mathrm{M}$-enabled MADM can be defined as:

$$
\left(D^{3} \text { M-enabled MADM }\right)=(\text { Mind Mining })+(\text { Data Mining })+\left(D^{3} M \text {-enabled Modelling }\right),
$$

where Mind Mining involves surveys or interviews, Data Mining refers to any sourcing of model parameters, such as investigation, crawling, analysis, or knowledge discovery for the heterogeneous data sources (so-called 'big data models' can be used for this purpose) and $D^{3} M$-enabled Modelling involves using a suitable $D^{3} M$-enabled MADM model, such as the AHP-hybrid models or any IF-MADM model, to solve the problem, similarly to the way in which the decision models are applied in this study to solve a group decision problem.

\section{Acknowledgments}

This research received funding supports from the following grants: Ministry of Science and Technology, Taiwan (ROC) (Project No.: MOST107-2410-H-992-046), UM Research Grant, Universidade de Macau (Project No.: CPG2015-00017-FST). 


\section{References}

Akaa, O. U., Abu, A., Spearpoint, M., \& Giovinazzi, S. (2016). A group-AHP decision analysis for the selection of applied fire protection to steel structures. Fire Safety Journal, 86, 95-105. https://doi.org/10.1016/j.firesaf.2016.10.005

Atanassov, K. (1986). Intuitionistic fuzzy sets. Fuzzy Sets and Systems, 20(1), 87-96. https://doi.org/10.1016/S0165-0114(86)80034-3

Atanassov, K., \& Gargov, G. (1989). Interval valued intuitionistic fuzzy sets. Fuzzy sets and systems, 31(3), 343-349. https://doi.org/10.1016/0165-0114(89)90205-4

Atanassov, K., Pasi, G., \& Yager, R. (2005). Intuitionistic fuzzy interpretations of multi-criteria multiperson and multi-measurement tool decision making. International Journal of Systems Science, 36(14), 859-868. https://doi.org/10.1080/00207720500382365

Azaiez, M. N., \& Al Sharif, S. S. (2005). A 0-1 goal programming model for nurse scheduling. Computers \& Operations Research, 32(3), 491-507. https://doi.org/10.1016/S0305-0548(03)00249-1

Bali, O., Dagdeviren, M., \& Gumus, S. (2015). An integrated dynamic intuitionistic fuzzy MADM approach for personnel promotion problem. Kybernetes, 44(10), 1422-1436.

https://doi.org/10.1108/K-07-2014-0142

Bao, Q., Ruan, D., Shen, Y., Hermans, E., \& Janssens, D. (2012). Improved hierarchical fuzzy TOPSIS for road safety performance evaluation. Knowledge-Based Systems, 32, 84-90. https://doi.org/10.1016/j.knosys.2011.08.014

Bayrak, M. Y., Çelebi, N., \& Taşkin, H. (2007). A fuzzy approach method for supplier selection. Production Planning and Control: the Management of Operations, 18(1), 54-63. https://doi.org/10.1080/09537280600940713

Beisgen, B., \& Kraitchman, M. (2003). Senior centers: opportunities for successful aging. New York: Springer Publishing Company.

Bhattacherjee, A. (2012). Social science research: principles, methods, and practices. University of South Florida Scholar Commons, USA.

Bian, T., Hu, J., \& Deng, Y. (2017). Identifying influential nodes in complex networks based on AHP. Physica A: Statistical Mechanics and its Applications, 479, 422-436. https://doi.org/10.1016/j.physa.2017.02.085

Boran, F. E., Boran, K., \& Menlik, T. (2012). The evaluation of renewable energy technologies for electricity generation in Turkey using intuitionistic fuzzy TOPSIS. Energy Sources, Part B: Economics, Planning, and Policy, 7, 81-90. https://doi.org/10.1080/15567240903047483

Boran, F. E., Genç, S., \& Akay, D. (2011). Personnel selection based on intuitionistic fuzzy sets. Human Factors and Ergonomics in Manufacturing \& Service Industries, 21(5), 493-503. https://doi.org/10.1002/hfm.20252

Boran, F. E., Genç, S., Kurt, M., \& Akay, D. (2009). A multi-criteria intuitionistic fuzzy group decision making for supplier selection with TOPSIS method. Expert Systems with Applications, 36(8), 11363 11368. https://doi.org/10.1016/j.eswa.2009.03.039

Borji, H. S. (2016). 4 global economic issues of an aging population. In Investopedia. Retrieved from http://www.investopedia.com/articles/investing/011216/4-global-economic-issues-aging-population.asp

Bryman, A. (2015). Social research methods. USA: Oxford University Press.

Bryman, A., \& Bell, E. (2015). Business research methods. USA: Oxford University Press.

Chang, C.-T., Chen, H.-M., \& Zhuang, Z.-Y. (2012) Revised multi-segment goal programming: percentage goal programming. Computers and Industrial Engineering, 63(4), 1235-1242.

https://doi.org/10.1016/j.cie.2012.08.005 
Charnes, A., Cooper, W. W., \& Ferguson, R. O. (1955). Optimal estimation of executive compensation by linear programming. Management Science, 1(2), 138-151. https://doi.org/10.1287/mnsc.1.2.138

Chen, S.-J., Hwang, C.-L., \& Hwang F.-P. (1992) Fuzzy multiple attribute decision making: Methods and applications. Berlin Heidelberg: Springer-Verlag. https://doi.org/10.1007/978-3-642-46768-4

Chen, T.-Y. (2015). The inclusion-based TOPSIS method with interval-valued intuitionistic fuzzy sets for multiple criteria group decision making. Applied Soft Computing, 26, 57-73. https://doi.org/10.1016/j.asoc.2014.09.015

Chen, T.-Y., Li, Y.-J., \& Wang, H.-P. (2011). A dissonance reduction method for intuitionistic fuzzy multi-criteria decision-making problems. Pan-Pacific Management Review, 14(1), 1-27.

Chen, S. M., \& Tan, J. M. (1994). Handling multicriteria fuzzy decision-making problems based on vague set theory. Fuzzy Sets and Systems, 67(2), 163-172. https://doi.org/10.1016/0165-0114(94)90084-1

Chi, L.-P., Zhuang, Z.-Y., Fu, C.-H., \& Huang J.-H. (2018). A Knowledge Discovery Education Framework Targeting the Effective Budget Use and Opinion Explorations in Designing Specific High Cost Product. Sustainability, 10(8), 2742. https://doi.org/10.3390/su10082742

Das, S., Kar, M. B., \& Kar, S. (2013). Group multi-criteria decision making using intuitionistic multifuzzy sets. Journal of Uncertainty Analysis and Applications, 1(10), 1-16. https://doi.org/10.1186/2195-5468-1-10

Dong, Q., \& Cooper, O. An orders-of-magnitude AHP supply chain risk assessment framework. International Journal of Production Economics, 182, 144-156. https://doi.org/10.1016/j.ijpe.2016.08.021

Dönmez, D. (2015). Social science methods for empirical data collection and analysis. Retrieved from http://www.timgroup.ethz.ch/download.php?ukey=1OTBevOhFjKzk66ABkPSKTlMb7KAz44rINS M9wUEGv4Rr1hSbXBLGMoHJZ89T2qs

Dweiri, F., Kumar, S., Khan, S. A., \& Jain, V. (2016). Designing an integrated AHP based decision support system for supplier selection in automotive industry. Expert Systems with Applications, 62, 273-283. https://doi.org/10.1016/j.eswa.2016.06.030

Erdogan, S. A., Šaparauskas, J., \& Turskis, Z. (2017). Decision making in construction management: AHP and expert choice approach. Procedia Engineering, 172, 270-276. https://doi.org/10.1016/j.proeng.2017.02.111

Fernández, J. F. G., \& Márquez, A. C. (2012). Managing maintenance strategy. In Maintenance management in network utilities: framework and practical implementation. Springer Science \& Business Media. https://doi.org/10.1007/978-1-4471-2757-4_6

Frege, C. M. (2005). Varieties of industrial relations research: take-over, convergence or divergence? British Journal of Industrial Relations, 43(2), 179-207. https://doi.org/10.1111/j.1467-8543.2005.00351.x

Gong, Z., Xu, X., Yang, Y., Zhou, Y., \& Zhang, H. (2016). The spherical distance for intuitionistic fuzzy sets and its application in decision analysis. Technological and Economic Development of Economy, 22(3), 393-415. https://doi.org/10.3846/20294913.2016.1181684

Govindan, K., \& Jepsen, M. B. (2016). ELECTRE: A comprehensive literature review on methodologies and applications. European Journal of Operational Research, 250(1), 1-29.

https://doi.org/10.1016/j.ejor.2015.07.019

Govindan, K., Kaliyan, M., Kannan D., \& Haq A. N. (2014). Barriers analysis for green supply chain management implementation in Indian industries using analytic hierarchy process. International Journal of Production Economics, 147, 555-568. https://doi.org/10.1016/j.ijpe.2013.08.018

Gruber, J., \& Wise, D. (2001). An international perspective on policies for an aging society (Working Paper No. 8103). National Bureau of Economic Research, US. https://doi.org/10.3386/w8103

Gupta, H., \& Barua, M. K. (2017). Supplier selection among SMEs on the basis of their green innovation ability using BWM and fuzzy TOPSIS. Journal of Cleaner Production, 152, 242-258.

https://doi.org/10.1016/j.jclepro.2017.03.125 
Hanne, T. (2013). Meta decision problems in multiple criteria decision making. In T. Gal, T. Stewart, \& T. Hanne (Eds.), Multicriteria Decision Making: advances in MCDM models, algorithms, theory, and applications (Vol. 21). Springer Science \& Business Media.

He, Y. H., Wang, L. B., He, Z. Z., \& Xie, M. (2016). A fuzzy TOPSIS and rough set based approach for mechanism analysis of product infant failure. Engineering Applications of Artificial Intelligence, 47, 25-37. https://doi.org/10.1016/j.engappai.2015.06.002

Hillerman, T., Souza, J. C. F., Reis, A. C. B., \& Carvalho, R. N. (2017). Applying clustering and AHP methods for evaluating suspect healthcare claims. Journal of Computational Science, 19, 97-111. https://doi.org/10.1016/j.jocs.2017.02.007

Ho, H.-P., Chang, C.-T., \& Ku, C.-Y. (2013). On the location selection problem using analytic hierarchy process and multi-choice goal programming. International Journal of Systems Science, 44(1), 94-108. https://doi.org/10.1080/00207721.2011.581397

Hossain, M. F., Adnan, Z. H., \& Hasin, M. (2014). Improvement in weighting assignment process in Analytic Hierarchy Process by introducing suggestion matrix and Likert scale. International Journal of Supply Chain Management, 3(4), 91-95.

Huang, J., Zhao, Y., \& Li, B. (2012). The application of intuitionistic fuzzy MADM based on projection model in thread threat assessment. In Lei et al. (Eds.), International Conference on Artificial Intelligence and Computational Intelligence 2012 (pp. 500-505). Springer-Verlag Berlin Heidelberg.

Hwang, C.-L., \& Yoon, K. (1981). Multiple attribute decision making: methods and applications. New York: Springer-Verlag. https://doi.org/10.1007/978-3-642-48318-9

Hwang, C.-L., Lai, Y.-J., \& Liu, T.-Y. (1993) A new approach for multiple objective decision making. Computers and Operational Research, 20, 889-899. https://doi.org/10.1016/0305-0548(93)90109-V

IBM. (2018). IBM Watson Health: Empowering Heroes, Transforming Health. Retrieved February, 2018, from URL: https://www.ibm.com/watson/health/

Janic, M., \& Reggiani, A. (2002). An application of the multiple criteria decision making (MCDM) analysis to the selection of a new hub airport. European Journal of Transport and Infrastructure Research, 2(2), 113-142.

Kahraman, C. (Ed.). (2008). Fuzzy multi-criteria decision making: theory and applications with recent developments (Vol. 16). Springer Science \& Business Media. https://doi.org/10.1007/978-0-387-76813-7

Kahraman, C., Onar, S. C., \& Oztaysi, B. (2015). Fuzzy multicriteria decision-making: a literature review. International Journal of Computational Intelligence Systems, 8(4), 637-666.

https://doi.org/10.1080/18756891.2015.1046325

Kang, D., Jang, W., \& Park, Y. (2016). Evaluation of e-commerce websites using fuzzy hierarchical TOPSIS based on ES-QUAL. Applied Soft Computing, 42, 53-65.

https://doi.org/10.1016/j.asoc.2016.01.017

Kannan, D., de Sousa Jabbour, A. B. L., \& Jabbour, C. J. C. (2014). Selecting green suppliers based on GSCM practices: Using fuzzy TOPSIS applied to a Brazilian electronics company. European Journal of Operational Research, 233(2), 432-447. https://doi.org/10.1016/j.ejor.2013.07.023

Kokangül, A., Polat, U., \& Dağsuyu, C. (2017). A new approximation for risk assessment using the AHP and Fine Kinney methodologies. Safety Science, 91, 24-32. https://doi.org/10.1016/j.ssci.2016.07.015

Kuo, R. J., Wu, Y. H., \& Hsu, T. S. (2012). Integration of fuzzy set theory and TOPSIS into HFMEA to improve outpatient service for elderly patients in Taiwan. Journal of the Chinese Medical Association, 75(7), 341-348. https://doi.org/10.1016/j.jcma.2012.05.001

Li, D. F. (2005). Multi-attribute decision making models and methods using intuitionistic fuzzy sets. Journal of Computer and System Sciences, 70, 73-85. https://doi.org/10.1016/j.jcss.2004.06.002 
Li, D. F. (2010). TOPSIS-based nonlinear-programming methodology for multiattribute decision making with interval-valued intuitionistic fuzzy sets. IEEE Transactions on Fuzzy Systems, 18(2), 299311. https://doi.org/10.1109/TFUZZ.2010.2041009

Li, D. F., Chen, G. H., \& Huang, Z. G. (2010). Linear programming method for multiattribute group decision making using IF sets. Information Sciences, 180, 1591-1609. https://doi.org/10.1016/j.ins.2010.01.017

Li, D. F., \& Nan, J. X. (2011). Extension of the TOPSIS for multi-attribute group decision making under Atanassov IFS environments. International Journal of Fuzzy System Applications, 1(4), 47-61. https://doi.org/10.4018/ijfsa.2011100104

Li, G., Kou, G., Lin, C., Xu, L., \& Liao, Y. (2015). Multi-attribute decision making with generalized fuzzy numbers. Journal of the Operational Research Society, 66(11), 1793-1803. https://doi.org/10.1057/jors.2015.1

Li, W., Yu, S., Pei, H., Zhao, C., \& Tian, B. (2017). A hybrid approach based on fuzzy AHP and 2-tuple fuzzy linguistic method for evaluation in-flight service quality. Journal of Air Transport Management, 60, 49-64. https://doi.org/10.1016/j.jairtraman.2017.01.006

Lin, L., Yuan, X. H., \& Xia, Z. Q. (2007). Multicriteria fuzzy decision-making methods based on intuitionistic fuzzy sets. Journal of Computer and System Sciences, 73, 84-88. https://doi.org/10.1016/j.jcss.2006.03.004

Liu, S., Chan, F. T., \& Ran, W. (2013). Multi-attribute group decision-making with multi-granularity linguistic assessment information: An improved approach based on deviation and TOPSIS. Applied Mathematical Modelling, 37(24), 10129-10140. https://doi.org/10.1016/j.apm.2013.05.051

Liu, C. H., Tzeng, G. H., \& Lee, M. H. (2012). Improving tourism policy implementation - the use of hybrid MCDM models. Tourism Management, 33(2), 413-426.

https://doi.org/10.1016/j.tourman.2011.05.002

Ma, L.-C. (2010). Visualizing preferences on spheres for group decisions based on multiplicative preference relations. European Journal of Operational Research, 203(1), 176-184. https://doi.org/10.1016/j.ejor.2009.07.008

Mahdevari, S., Shahriar, K., \& Esfahanipour, A. (2014). Human health and safety risks management in underground coal mines using fuzzy TOPSIS. Science of the Total Environment, 488, 85-99. https://doi.org/10.1016/j.scitotenv.2014.04.076

Majumder, M. (2015). Multi criteria decision making. In: Impact of urbanization on water shortage in face of climatic aberrations (pp. 35-47). Singapore: Springer. https://doi.org/10.1007/978-981-4560-73-3_2

Mardani, A., Jusoh, A., MD Nor, K., Khalifah, Z., Zakwan, N., \& Valipour, A. (2015). Multiple criteria decision-making techniques and their applications-a review of the literature from 2000 to 2014. Economic Research-Ekonomska Istraživanja, 28(1), 516-571.

https://doi.org/10.1080/1331677X.2015.1075139

Márquez, A. C. (2007). Criticality analysis for asset priority setting. In The maintenance management framework: models and methods for complex systems maintenance. Springer Science \& Business Media.

Marr, B. (2016). Big data in practice. US: Wiley. https://doi.org/10.1002/9781119278825

McAfee, A., Brynjolfsson, E., Davenport, T. H., Patil, D. J., \& Barton, D. (2012). Big data: the management revolution. Harvard Business Review, 90(10), 61-67.

Mir, M. A., Ghazvinei, P. T., Sulaiman, N. M. N., Basri, N. E. A., Saheri, S., Mahmood, N. Z., Jahan, A., Begum, R. A., \& Aghamohammadi, N. (2016). Application of TOPSIS and VIKOR improved versions in a multi criteria decision analysis to develop an optimized municipal solid waste management model. Journal of Environmental Management, 166, 109-115.

https://doi.org/10.1016/j.jenvman.2015.09.028 
Nikou, S., \& Mezei, J. (2013) Evaluation of mobile services and substantial adoption factors with analytic hierarchy process (AHP). Telecommunications Policy, 37(10), 915-929.

https://doi.org/10.1016/j.telpol.2012.09.007

Oh, S. O., \& Park, J. W. (2014). A study on relative importance and priority regarding airport selection attributes utilizing AHP. International Journal of Business and Social Research, 4(10), 43-53.

Opricovic, S., \& Tzeng, G. H. (2004). Compromise solution by MCDM methods: A comparative analysis of VIKOR and TOPSIS. European Journal of Operational Research, 156(2), 445-455. https://doi.org/10.1016/S0377-2217(03)00020-1

Opricovic, S., \& Tzeng, G. H. (2007). Extended VIKOR method in comparison with outranking methods. European Journal of Operational Research, 178(2), 514-529. https://doi.org/10.1016/j.ejor.2006.01.020

Ouyang, Y., \& Pedrycz, W. (2016). A new model for intuitionistic fuzzy multi-attributes decision making. European Journal of Operational Research, 249, 677-682. https://doi.org/10.1016/j.ejor.2015.08.043

Oztaysi, B., Onar, S. C., Kahraman, C., \& Yavuz, M. (2017). Multi-criteria alternative-fuel technology selection using interval-valued intuitionistic fuzzy sets. Transportation Research Part D, 53, 128-148. https://doi.org/10.1016/j.trd.2017.04.003

Pankowska, A., \& Wygralak, M. (2006) General IF-sets with triangular norms and their applications to group decision-making. Information Sciences, 176(18), 2713-2754. https://doi.org/10.1016/j.ins.2005.11.011

Park, J. H., Park, I. Y., Kwun, Y. C., \& Tan, X. (2011) Extension of the TOPSIS method for decision making problems under interval-valued intuitionistic fuzzy environment. Applied Mathematical Modelling, 35(5), 2544-2556. https://doi.org/10.1016/j.apm.2010.11.025

PennState University Libraries. (2017). Empirical research in education and the behavioral/social sciences. Retrieved February 2018, from URL: http://guides.libraries.psu.edu/emp

Ramanathan, R., Mathirajan, M., \& Ravindran, A. R. (Eds.). (2017). Big data analytics using multiple criteria decision-making models. Boca Raton: CRC Press. https://doi.org/10.1201/9781315152653

Reinartz, W., Haenlein, M., \& Henseler, J. (2009). An empirical comparison of the efficacy of covariance-based and variance-based SEM. International Journal of Research in Marketing, 26(4), 332-344. https://doi.org/10.1016/j.ijresmar.2009.08.001

Ren, H., \& Wang, G. (2015). An interval-valued intuitionistic fuzzy MADM method based on a new similarity measure. Information, 6(4), 880-894. https://doi.org/10.3390/info6040880

Research Center of Industry Innovation for the Senior Citizens. (2012). CGURP-UARPD-3A0101: Final Term Report. Chang Gung University. Retrieved from http://memo.cgu.edu.tw/rciis/Research.html

Roy, B. (1991). The outranking approach and the foundations of ELECTRE methods. Theory and Decision, 31(1), 49-73. https://doi.org/10.1007/BF00134132

Saaty, T. L. (1977). A scaling method for priorities in hierarchical structures. Journal of Mathematical Psychology, 15, 59-62. https://doi.org/10.1016/0022-2496(77)90033-5

Sabaei, D., Erkoyuncu, J., \& Roy, R. (2015). A review of multi-criteria decision making methods for enhanced maintenance delivery. Procedia CIRP, 37, 30-35. https://doi.org/10.1016/j.procir.2015.08.086

Sadiq, R., \& Tesfamariam, S. (2009). Environmental decision-making under uncertainty using intuitionistic fuzzy analytic hierarchy process (IF-AHP). Stochastic Environmental Research and Risk Assessment, 23(1), 75-91. https://doi.org/10.1007/s00477-007-0197-Z

Samuel, O. W., Asogbon, G. M., Sangaiah, A. K., Fang, P., \& Li, G. (2017). An integrated decision support system based on ANN and Fuzzy AHP for heart failure risk prediction. Expert Systems with Applications, 68, 163-172. https://doi.org/10.1016/j.eswa.2016.10.020

Sasanka, C. T., \& Ravindra, K. (2015). Implementation of VIKOR method for selection of magnesium alloy to suit automotive applications. International Journal of Advanced Science and Technology, 83, 49-58. https://doi.org/10.14257/ijast.2015.83.05 
Sayadi, M. K., Heydari, M., \& Shahanaghi, K. (2009). Extension of VIKOR method for decision making problem with interval numbers. Applied Mathematical Modelling, 33(5), 2257-2262.

https://doi.org/10.1016/j.apm.2008.06.002

Schrage, L. (2002). LINGO Release 8.0 Users Manual. Chicago: LINDO System, Inc.

Shannon, C. E. (1948). A mathematical theory of communication. Bell System Technical Journal, 27, 379-423. https://doi.org/10.1002/j.1538-7305.1948.tb01338.x

Singh, D., \& Rao, R. (2011). A hybrid multiple attribute decision making method for solving problems of industrial environment. International Journal of Industrial Engineering Computations, 2(3), 631644. https://doi.org/10.5267/j.ijiec.2011.02.001

Simon, H. A. (1976). Administrative behavior: a study of decision-making processes in administrative organization. New York: Free Press.

Szmidt, E., \& Kacprzyk, J. (1996). Intuitionistic fuzzy sets in group decision making. Notes on IFS, 2(1), 15-32.

Szulecka, J., \& Zalazar, E. M. (2017). Forest plantations in Paraguay: Historical developments and a critical diagnosis in a SWOT-AHP framework. Land Use Policy, 60, 384-394.

https://doi.org/10.1016/j.landusepol.2016.11.001

Triantaphyllou, E. (2000). Chapter 2: Multi-criteria decision making methods. In Multi-criteria decision making methods: A comparative study (pp. 5-21). US: Springer.

https://doi.org/10.1007/978-1-4757-3157-6_2

Tzeng, G.-H., \& Huang, J.-J. (2011). Multiple attribute decision making: methods and applications. CRC Press, Taylor \& Francis Group.

Velasquez, M., \& Hester, P. T. (2013). An analysis of multi-criteria decision making methods. International Journal of Operations Research, 10(2), 56-66.

Vlachos, I. K., \& Sergiadis, G. D. (2007). Intuitionistic fuzzy information - Applications to pattern recognition. Pattern Recognition Letters, 28, 197-206. https://doi.org/10.1016/j.patrec.2006.07.004

Walczak, D., \& Rutkowska, A. (2017). Project rankings for participatory budget based on the fuzzy TOPSIS method. European Journal of Operational Research, 260(2), 706-714. https://doi.org/10.1016/j.ejor.2016.12.044

Wang, C.-Y., \& Chen, S.-M. (2017). Multiple attribute decision making based on interval-valued intuitionistic fuzzy sets, linear programming methodology, and the extended TOPSIS method. Information Sciences, 397, 155-167. https://doi.org/10.1016/j.ins.2017.02.045

Wang, S.-P., Hsieh, Y.-K., Zhuang, Z.-Y., \& Ou, N.-C. (2014). Solving an outpatient nurse scheduling problem by binary goal programming. Journal of Industrial and Production Engineering, 31(1), 4150. https://doi.org/10.1080/21681015.2014.881425

Wang, X., \& Peng, B. (2015). Determining the value of the port transport waters: Based on improved TOPSIS model by multiple regression weighting. Ocean \& Coastal Management, 107, 37-45. https://doi.org/10.1016/j.ocecoaman.2015.02.004

Wei, W., Liang, J., Wang, J., \& Qian, Y. (2013). Decision-relative discernibility matrices in the sense of entropies. International Journal of General Systems, 42(7), 721-738. https://doi.org/10.1080/03081079.2013.781166

$\mathrm{Xu}, \mathrm{Z}$. (2007). Intuitionistic preference relations and their applications in group decision making. Information Sciences, 177(1), 2363-2379. https://doi.org/10.1016/j.ins.2006.12.019

$\mathrm{Xu}, \mathrm{Z}$. (2011). Approaches to multiple attribute group decision making based on intuitionistic fuzzy power aggregation operators. Knowledge-Based Systems, 24, 749-760. https://doi.org/10.1016/j.knosys.2011.01.011

Xu, Z., \& Liao, H. (2014). Intuitionistic fuzzy analytic hierarchy process. IEEE Transactions on Fuzzy Systems, 22(4), 749-761. https://doi.org/10.1109/TFUZZ.2013.2272585 
Xu, Z., \& Yager, R. R. (2008). Dynamic intuitionistic fuzzy multi-attribute decision making. International Journal of Approximate Reasoning, 48(1), 246-262. https://doi.org/10.1016/j.ijar.2007.08.008

Xu, Y., Wang, Y., \& Miu, X. (2012). Multi-attribute decision making method for air target threat evaluation based on intuitionistic fuzzy sets. Journal of Systems Engineering and Electronics, 23(6), 891897. https://doi.org/10.1109/JSEE.2012.00109

Yang, Y., \& Chiclana, F. (2009). Intuitionistic fuzzy sets: spherical representation and distances. International Journal of Intelligent Systems, 24, 399-420. https://doi.org/10.1002/int.20342

Yang, J.-B., \& Madan, G. S. (1994). An evidential reasoning approach for multiple-attribute decision making with uncertainty. IEEE Transactions on Systems, Man and Cybernetics, 24(1), 1-18. https://doi.org/10.1109/21.259681

Yazdani, M., \& Payam, A. F. (2015). A comparative study on material selection of microelectromechanical systems electrostatic actuators using Ashby, VIKOR and TOPSIS. Materials \& Design (19802015), 65, 328-334. https://doi.org/10.1016/j.matdes.2014.09.004

Ye, F. (2010). An extended TOPSIS method with interval-valued intuitionistic fuzzy numbers for virtual enterprise partner selection. Expert Systems with Applications, 37(10), 7050-7055. https://doi.org/10.1016/j.eswa.2010.03.013

Ye, J. (2013). Multiple attribute group decision-making methods with unknown weights in intuitionistic fuzzy setting and interval valued intuitionistic fuzzy setting. International Journal of General Systems, 42(5), 489-502. https://doi.org/10.1080/03081079.2013.775127

Yu, P. L. (1973). A class of solutions for group decision problems. Management Science, 19(8), 936-946. https://doi.org/10.1287/mnsc.19.8.936

Zadeh, L. A. (1965). Fuzzy sets. Information and Control, 8(3), 338-353. https://doi.org/10.1016/S0019-9958(65)90241-X

Zavadskas, E. K., Turskis, Z., \& Kildienė, S. (2014). State of art surveys of overviews on MCDM/MADM methods. Technological and Economic Development of Economy, 20(1), 165-179.

https://doi.org/10.3846/20294913.2014.892037

Zeleny, M. (2011). Multiple criteria decision making (MCDM): From paradigm lost to paradigm regained? Journal of Multi-criteria Decision Analysis, 18(1-2), 77-89. https://doi.org/10.1002/mcda.473

Zhang, N., \& Wei, G. (2013). Extension of VIKOR method for decision making problem based on hesitant fuzzy set. Applied Mathematical Modelling, 37(7), 4938-4947.

https://doi.org/10.1016/j.apm.2012.10.002

Zhao, X. (2014). TOPSIS method for interval-valued intuitionistic fuzzy multiple attribute decision making and its application to teaching quality evaluation. Journal of Intelligent \& Fuzzy Systems, 26(6), 3049-3055.

Zhou, S., Liu, W., \& Chang, W. (2016). An improved TOPSIS with weighted hesitant vague information. Chaos, Solitons \& Fractals, 89, 47-53. https://doi.org/10.1016/j.chaos.2015.09.018

Zhuang, Z. Y., Chiang, I. J., Su, C. R., \& Chen, C. Y. (2017) Modelling the decision of paper shredder selection using analytic hierarchy process and graph theory and matrix approach. Advances in Mechanical Engineering, 9(12), 1-11. https://doi.org/10.1177/1687814017737668

Zhuang, Z. Y., \& Hocine, A. (2018). Meta goal programing approach for solving multi-criteria de Novo programing problem. European Journal of Operational Research, 265(1), 228-238.

https://doi.org/10.1016/j.ejor.2017.07.035

Zhuang, Z.-Y., Yang, L.-W., Lee, M.-H., \& Wang, C.-Y. (2018). 'MEAN+R': implementing a web-based, multi-participant decision support system using the prevalent MEAN architecture with $\mathrm{R}$ based on a revised intuitionistic-fuzzy multiple attribute decision-making model. Microsystem Technologies, 24(10), 4291-4309. https://doi.org/10.1007/s00542-018-3755-Z 


\section{APPENDIX A}

Three Taiwanese quasi-seniors, who had been high school classmates and who are all 50+ years old with established careers discussed that was of interest to all of them:

$\mathrm{DM}^{\mathrm{A}}$ : “There are so many senior centres nowadays. I am now a healthy senior. How do I choose a suitable senior center with only a few years left to make the decision?"

$\mathrm{DM}^{\mathrm{B}}$ : "I also will not want to live at home then. I am tired of living with my daughter in law so if I can afford it, I will definitely live in a senior centre. Why not live together?"

$\mathrm{DM}^{\mathrm{C}}$ : "It's good to have sons or daughters and you have a choice to visit them. For me and my wife, senior center residence is a must! So we will look around first and choose a proper one and then visit it!"

As such, selecting a senior center in which to live together in the future, based on the three quasi-seniors' common opinions, is a typical group decision problem.

\section{APPENDIX B}

The criteria and alternatives are determined as follows. A literature review (CGU Research Center of Industry Innovation for the Senior Citizens, 2012) shows that 14 factors affect senior centre selection. In this study, these factors are defined as the sub-decision criteria, and according to their properties, they are categorized into 5 main constructs, $C_{1}-C_{5}$, for senior centre selection. These 5 constructs are financial concerns, environmental concerns, facility level, service level and conveniences concerns.

Since the interviewed quasi-senior DMs are from Taiwan, the alternative set for this study (i.e., $\left.A l t_{1}-A l t_{4}\right)$ contains 4 representative senior centres in Taiwan, which are also chosen from the abovementioned survey report. The report also provides the raw data for the 14 decision factors (based on an ex-survey) for the 4 chosen alternatives, which are also retrieved and used for modelling. These are shown in Table 1.

\section{APPENDIX C}

As discussed in Appendix B, the source data only contains observations of the alternatives for each of the 14 sub-criteria (i.e., the decision factors). Some of these are numerical values and others are not, depending on the property of the sub-criterion, such as a description of whether an alternative has some specific features/function or not. These nominal representations must firstly be transformed into cardinal representations and then normalized. These cardinal evaluations can be normalized directly at the $[0,1]$ interval, using bi-polar linearization. For example, for 'in-room facilities', which is a sub-criterion of the 'facility-level' construct, this is done by counting how many types of in-room facilities that a senior center provides and then normalizing these cardinal counts within the range $[0,1]$. 


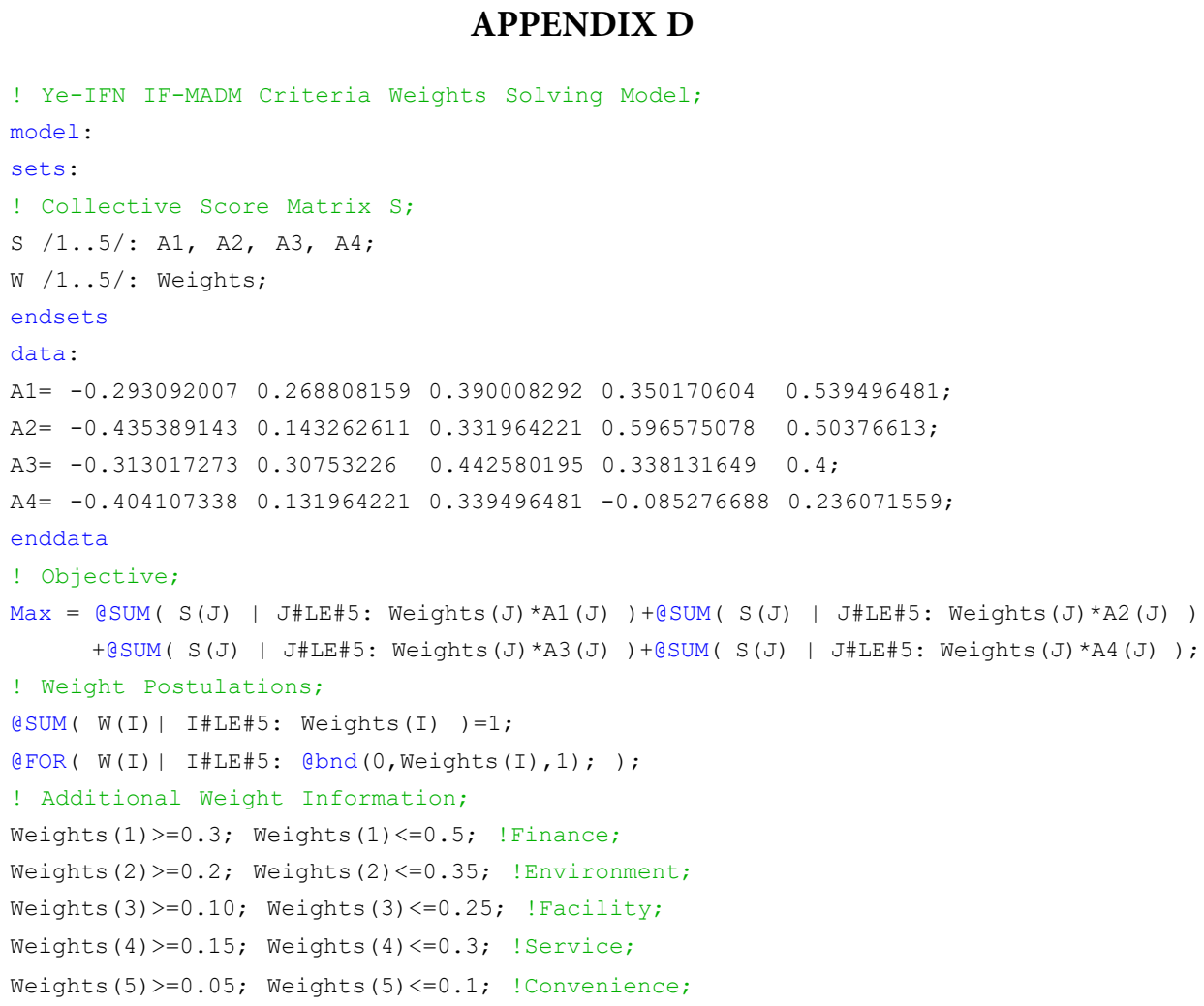

In this model, the first code section (i.e., the data and sets) stipulates and defines the data. The known matrix, $S$, and the decision vector $W_{\text {IFN }}$ are defined. The second section is the objective function, followed by a third hard constraint section for weight postulation. Finally, a soft constraint section formulates the possible ranges of the weights for the criteria, using the information offered by the 3 DMs who discussed these issues.

Using the LP model, the optimal criteria weight vector, $W_{\text {IFN }}^{*}$, maximizes the summation of the SAW results for each individual alternative. In this study, the summation assumes that all of the alternatives are equally important because at this stage, none of them dominates.

\section{APPENDIX E}

In 3.2 (Table 4), using AHP, in order to obtain the average CWV, the geometric means of the individual weight values (of the DMs) are calculated. The averaged CWV consists of these result values and is further normalized. This process does not involve powering any individual criterion weight of any DM. The process, in itself, implies that using a standard AHP, all of the DMs' opinions are assumed to be equally important, so it is possible to compare the OWVs, as obtained and assumed, respectively. 